Article

\title{
Predictable and Unpredictable Climate Variability Impacts on Optimal Renewable Energy Mixes: The Example of Spain
}

\author{
Aina Maimó-Far ${ }^{1, * \mathbb{C}}$, Alexis Tantet ${ }^{2}{ }^{\mathbb{D}}$, Víctor Homar ${ }^{1}{ }^{\mathbb{D}}$ and Philippe Drobinski ${ }^{2}$ \\ 1 Physics Department, Meteorology Group, Universitat de les Illes Balears, 07122 Palma de Mallorca, Spain; \\ victor.homar@uib.cat \\ 2 LMD/IPSL, Ecole Polytechnique, IP Paris, ENS, PSL Université, Sorbonne Université, CNRS, \\ 91120 Palaiseau, France; alexis.tantet@lmd.polytechnique.fr (A.T.); \\ philippe.drobinski@lmd.polytechnique.fr (P.D.) \\ * Correspondence: aina.maimo@uib.cat
}

Received: 4 August 2020; Accepted: 25 September 2020; Published: 2 October 2020

\begin{abstract}
We analyzed the role of predictable and unpredictable variability in the identification of optimal renewable energy mixes in an electricity system. Renewable energy sources are the fastest growing energy generation technology, but the variable nature of production linked to climate variability raises structural, technological and economical issues. This work proposes the differentiation of the treatment applied to predictable and unpredictable variability in the context of Markowitz portfolio theory for optimal renewable deployment. The e4clim model was used as a tool to analyze the impact of predictable sources of generation variability on the optimal renewable energy mixes. Significant differences appeared, depending on the consideration of risk, all of them showing room for improvement with respect to the current situation. The application of the methods developed in this study is encouraged in mean-variance analyses, since its contribution favors scenarios where unpredictable variability in the climate-powered renewable energy sources are considered for their risk introduction.
\end{abstract}

Keywords: renewable energy; mean-variance analysis; climate variability; PV generation; predictability

\section{Introduction}

According to the International Energy Agency (IEA) [1], in a scenario that incorporates the current policy intentions and targets, wind and solar photovoltaics (PV) become the most relevant renewable sources of energy. Demand is projected to grow by $1 \%$ each year to 2040, but more than half of this increase is covered by low-carbon sources, led by solar PV. The IEA [2] has reported an increase of almost 3\% in renewable electricity generation in the first three months of 2020 with respect to the same period of 2019. An increase of nearly 5\% is expected in 2020, and this expectation was even higher before the COVID-19 crisis. The COVID-19 crisis has also been related to drops exceeding $20 \%$ in electricity demand during times of full lockdown, which has translated into a decrease in the demand of fossil fuels but a rise in the demand of electricity from renewable sources, pointing to renewable generation as the most important energy source for a sustainable future. Independently of the recovery rate regarding the crisis, renewables are expected to continue experiencing an increase. More specifically, solar PV is the renewable energy source with the highest expected growth in 2020. Overall, in the path towards a renewable future, wind energy and solar PV are the most important sources according to the International Renewable Energy Agency (IRENA) [3].

Accordingly, the European Union (EU) is setting the guidelines at the European level for an efficient energy transition $[4,5]$. The goal is to achieve long-term climate neutrality, by having no net 
carbon emissions by 2050. For that, the EU has planned a path with intermediate objectives for its member states through setting targets for 2030 [6], including a 32\% renewable energy share and a decrease of at least $40 \%$ in greenhouse gas emissions with respect to 1990. The European Union is advancing in the achievement of the objectives, since 21 member states (including Spain) are complying with or exceeding the goals that marked this trajectory for the period 2017-2018.

Within Europe, the Mediterranean is an area especially susceptible to some aspects of climate change [7], and has had significantly greater consequences from some of its effects. For instance, the warming effect is stronger in the Mediterranean region [8], as well as unevenly distributed within the months of the year [9]. The United Nations Environment Programme (UNEP) [10] states that there is a need for an investment in renewable energy sources and an increase in their efficiency in the Mediterranean region, due to the need for an equilibrium in the use of food, water and energy. Therefore, it is highly fundamental for the Mediterranean to have an efficient renewable energy supply in the long run.

Countries in Europe have developed national plans to meet the EU goals. The path towards the 2050 climate neutrality cannot be fixed by the EU, but by individual countries. The Spanish plan [11] was successful in the 2017-2018 period and more ambitious goals are set towards 2030. In particular, the objectives are: $23 \%$ drop in greenhouse gas emissions with respect to 1990; $42 \%$ renewable energy at final use, doubling the $20 \%$ of $2020 ; 39.5 \%$ increase in energy efficiency in the next decade; and $74 \%$ renewable energy presence in the electricity sector, in accordance with the $100 \%$ goal for 2050 . An analysis of the implications that these types of objectives have on the energy system, specifically in the 2020 objective of $20 \%$ penetration, was carried out in Gómez et al. [12], also in the specific case of Spain.

In the particular case of Spain, investments are put towards understanding the relation of climate and the energy system. More specifically, the Spanish National Plan for Adaptation to Climate Change [13] puts forward the necessity to improve our understanding of the effects of climate on the renewable production and use this information in energy planning stages. Similarly, the climatic effects on the functionality and resilience of the different elements of the electricity system need to be understood in order to adapt these infrastructures to the final goal of reliable and stable generation. Even though this plan is meant to begin in 2021, the scientific community is already progressing towards this understanding of the electricity system. Datas et al. [14] found that PV and battery installation in buildings could have a very positive effect in individual consumers both in terms of fuel and economic savings. Santiago et al. [15] studied the efficiency of different PV cells to find the one that best suits southern Spain. Santos-Alamillos et al. [16] analyzed the importance of balancing PV and wind technologies in the south of the Iberian Peninsula. These types of studies that balance the deployment of PV and wind technology are of particular interest in a context which predicts a global increase in penetration for both technologies in the upcoming years $[17,18]$.

Grid integration of renewable energy is key for a successful electricity system and requires planning and management at all time scales [19]. This is where the concept of complementarity becomes fundamental. Complementarity can be temporal (storage) or spatial (grid), although no consensus definition for the concept exists [20]. A strong knowledge of how the complementarity works can help match generation curves to demand curves, whose mismatch poses one of the major problems in renewable deployment [21,22]. For instance, François et al. [23] studied the complementarity of run-of-river hydropower and PV in northern Italy, finding a strong dependency of the share with the time scale of interest. Raynaud et al. [24] found that using diverse energy sources in an energy mix helps reduce the frequency of energy droughts.

A method for the adaptation of an energy system to the climate characteristics of the regions is the Markowitz portfolio theory [25]. This approach aims to maximize the penetration of renewable energies while minimizing the risk, which is usually defined in terms of cost or generation variability. Tantet et al. [26] applied this theory to the different regions of Italy and showed the robustness of the general optimal penetrations to the different possible climate data sources; Zedda [21] used 
this method to maximize the penetration of a set of wind plants in Sardinia, finding possible a coverage of up to $94 \%$ of the demand if the optimal mix were to be used; Beltran [27] inferred the optimal renewable mix in Mexico, finding that the same risk could be achieved with lower cost and vice versa; Roques et al. [28] determined the optimal deployment among five European countries, shedding light on the importance of an interconnected grid in the European context; Roques et al. [29] studied the UK market from a more economical point of view, showing optimal scenarios in terms of electricity and $\mathrm{CO}_{2}$, and used a Monte Carlo approach to obtain the input data of the Portfolio from a model of investment, showing the variety of data origins that can be absorbed by this type of optimization; Thomaidis et al. [30] optimized the mix of concentrating solar power and wind in the Southern Iberian Peninsula, introducing the preference for risk or return of the portfolio manager; Santos-Alamillos et al. [31] explored wind repowering potential in Spain, while introducing different repowering scenarios considering realistic investments in the deployment of wind farms.

Using portfolio theory implies an approach where the return is maximized and the risk is minimized. However, the exact definition of return and risk may vary between different studies. Zedda [21] did not specify the methodology used, but adapted financial theory to the coverage of the demand curve by the different wind farm production approaches. Tantet et al. [26] found the optimal mixes for PV and wind through maximizing the share of the demand covered by renewable energy sources (penetration) and minimizing its variability in Italy; Beltran [27] did so for Mexico, Roques et al. [28] for a combination of European countries, Thomaidis et al. [30] for the Southern Iberian Peninsula, and Santos-Alamillos et al. [31] for the wind farms of Spain. However, this is not the only valid definition of the return and risk. Roques et al. [29] applied the optimization to the economics of renewables and took the net present value (difference between present value inflows and outflows, a sign of money return per unit of installed capacity) and found what would be the optimal mixes from the investor's point of view. Similarly, Muñoz et al. [32] for Spain and Marrero et al. [33], in a worldwide approach, optimized return in economical terms. On a similar note to the generation cases, Kitzing [34] maximized the Sharpe ratio (the mean-risk ratio of a resource) with respect to the different support levels (price levels that the renewable generation does not fall below). Another interesting approach taken in Heide et al. [35] aims at minimizing the storage energy capacity, the balancing energy, and the balancing power in their different combinations (this case is a double minimization instead of a parallel maximization and minimization, but the concept remains the same, as the two minimized quantities work in opposite ways).

In this context, a technology of particular interest, especially in the consideration of risk, is PV. PV is strongly predictable, with the main variation mode emerging from astronomical cycles [36]. Clouds are only second in the representation of the solar radiation variability, but are the main physical parameter for co-variability of surface solar radiation [37]. The instantaneous presence of clouds is unpredictable over climatic time-scales, unlike the astronomical radiation, which represents the predictable component of the radiation. All of this matches perfectly with the spectral analysis carried out in Lave and Kleissl [38] in four sites in the state of Colorado, which found that the highest energy periods are the 24-h and its harmonics (mainly 12, 8, 6, and $4 \mathrm{~h}$, in order of peak intensity). This effect is not explicitly accounted for in portfolio theory, where the entire variability of the surface radiation is considered as risk, ignoring the advantages of its predominant predictable component. The motivation of this study originated from the idea that the predictable nature of the largest component of PV generation is underutilized and that this characteristic can be explicitly accounted for when optimal mixes are pursued.

The predictable intermittency of PV generation can already be considered in the design of the system, and spatial (grid) and temporal (storage) variability of the renewable generation sources can be taken into account $[39,40]$. The large presence of renewable intermittent energy sources makes the installation of storage resources a valuable option, since the generation cannot be generally matched directly to the demand. The long-established fuel-based system, producing electricity when it is needed, led to an inefficient, over-designed, and expensive system [41]. The introduction of storage, 
especially in a context where the intermittency introduced by the renewable energy sources cannot be avoided, can simplify the balancing of production and demand, as it decouples generation and load [42], and brings with it an overall more stable electricity system. From a management and planning perspective, predictable variability can be translated to periods where energy will be saved or extracted from storage. Although unpredictable variability is easier to handle with storage, its erratic behavior yields distinct risks in the system, contrarily to predictable variability. Even though part of the unpredictable variability can be predicted in the climatic sense, the need for instantaneous satisfaction of the generation-demand balance requires more detailed knowledge of the variability of the electricity system components. The overall cost of renewable integration can be significantly reduced through improvements in the allocation of renewable generation plants [43] in order to provide more stable and predictable generation.

While prediction costs are usually found not to dominate the integration cost, it is still significant that they are minimized [44]. A deep knowledge of the predictable or unpredictable nature of the energy generation sources is key in reaching a mix with minimal prediction costs. In a mix with wind and PV as the renewable energy sources, PV shows a strong predictable component, whereas wind presents generally unpredictable behavior at hourly time scales. Taking this predictability into account presents a powerful approach that was not considered in the optimizations of existing studies. This aspect can contribute towards reaching more optimal mixes that better account for the variability introduced by the climate resource. Additionally, while some studies estimate prediction costs, they do not always take them into account in their optimization of energy mixes, and in particular, there is no apparent instance of studies differentiating the impacts of PV and wind on prediction costs and optimizing the mix while taking this differentiation into account.

The objective of this study was to discern the predictable and unpredictable variability of the radiation for PV generation in portfolio theory. Since the predictable variability can more effectively be accounted for at the planning stage, unpredictable variability should be distinctively considered in the risk definition in a portfolio context, thereby penalizing the unpredictable factors more in the risk assessment of an energy mix. A redefinition of PV risk in portfolio theory is proposed, where only the unpredictable nature of the PV generation is penalized in the optimization process. The proposed technique does not penalize regions for having strong daily cycles, a consideration that can help existing approaches take into consideration the strong difference in behavior between the two components and find more optimal mixes in an application that more closely resembles the actual behavior of PV generation.

The article is structured as follows. The models and data used are explained in Section 2 together with a definition of the predictable and unpredictable components of the risk. The impacts on mean-variance optimization of the proposed methodology are shown and discussed in Section 3. Section 4 gives an overview of the findings of this study and provides the concluding remarks.

\section{Methodology}

In this study, we use the energy for a climate integrated model (e4clim) presented in Tantet et al. [26] to analyze the impacts of climate variability on optimal renewable energy mixes, focusing on the development of a method for dealing with the risks that come from the presence of predictable and unpredictable variability components. e4clim strikes as the most suitable tool for this purpose for multiple reasons. First, it is focused on the climatic resource, which powers renewable energy generation and is its main source of variability. Second, it allows for a combination of hourly climate data at the resolution of the climate-data grid and regional electricity data, allowing one to get regional capacity-factor and demand estimations to optimize regional mixes. At its core, e4clim is a modeling platform to optimize renewable energy mixes regionally based on climatic features, which allows one to assess the sensitivity of optimal energy mixes to how the different elements in the generation and demand components are incorporated. Additionally, objectives of the optimization being defined heuristically (mean and variance, in the context of a mean-variance analysis, one of the 
possibilities offered by e4clim) allows us to focus on the variability of the production, while avoiding running a full power-system model to estimate system costs. We can thus focus on renewable energies, which facilitates sensitivity analyses.

\subsection{Data Used}

We used the The Modern-Era Retrospective Analysis for Research and Applications, Version 2 (MERRA-2) [45] reanalysis as our reference climate data. The temporal resolution of MERRA-2 data is one hour, with a grid of $0.625^{\circ}$ in longitude and $0.5^{\circ}$ in latitude. We used 20 years of climate data, spanning from 1999 to 2018 . In order to ensure representativity of the regionally aggregated series, administrative regions with low numbers of climatic points were clustered with larger neighboring administrative regions to form a larger modeled region. An example is the region of Cantabria, which we merged with Asturias to form the "Northern Iberian Peninsula" region in e4clim simulations. The use of calibration with observed electricity data to the model also helped correct these issues.

Spanish electricity data were obtained from Red Eléctrica de España (REE). Monthly regional renewable generation series were obtained, whereas only yearly regional demand series were available from REE. A calibration period, covered by uninterrupted quality-checked (using REE reports and API) data for both regional generation and demand covers the years 2014 to 2018. Regional installed capacity data for this period was also obtained from REE. Moreover, we also used REE hourly national demand series in the downscaling process of the yearly regional demand to hourly frequency. In particular, the national series was scaled to match the yearly total of the yearly regional series to render the regional hourly estimate.

\subsection{Model and Parameterizations}

The model calculates hourly wind and PV generation from climate data at each climate model gridpoint. The wind generation is modeled by passing the wind magnitude computed from the zonal and meridional wind and rescaled by the density to a power. The PV generation is parameterized from surface downward shortwave radiation and temperature, which is used to estimate the panel efficiency. A more detailed description of these models is given in the Appendix A.3 of Tantet et al. [26]. These calculated generations are then uniformly averaged over regions, the latter being the division present in the electricity system and the scale at which the system is to be optimized.

The temperature-dependent demand parameterization was fitted using the regional hourly demand series over the calibration period (see below), for which both electricity and climate data were available. We then applied the fitted demand function to the temperature data over the whole 20-year study period to obtain regional hourly demand series.

The capacity factors per region estimated from the climate data present biases coming from the climate data and model parameterizations, as well as the grouping over regions. We used observed electricity data to improve the regional capacity factors estimated from climate data. To do so, we performed linear regressions over the 5-year calibration period (2014-2018) for each region to estimate scaling factors relating the capacity factors computed from the climate data to the electricity data. We then applied this correction to the full 20-year study period to obtain the corrected generation series from each region. An instance of the importance of the calibration can be seen if a region is not particularly windy overall but has a specific area with sustained winds where wind farms are installed. In general, this region presents strong renewable potential even though it is unseen when the coarse climatic resolution and the homogeneity of the region are considered. The final inputs to the mean-variance optimization are hourly time series of demand, wind generation, and PV generation over the 1999-2018 study period.

The mean-variance analysis is an application of the portfolio selection introduced in economics by Markowitz [25]. This strategy, applied to energy mixes, aims at finding optimal combinations of installed capacities per region and technology that maximize the renewable energy penetration while minimizing the risk, based on the regional series of capacity factor and demand. The penetration of 
renewable generation sources is defined as the expected value of the ratio of total renewable generation over total demand:

$$
\mu=\mathbb{E}\left[\sum_{k} \omega_{k} \frac{\overrightarrow{\eta_{k}}}{\sum_{i} \vec{D}_{i}}\right]=\sum_{k} \omega_{k} \mathbb{E}\left[\frac{\overrightarrow{\eta_{k}}}{\sum_{i} \vec{D}_{i}}\right]
$$

The risk is defined here as the variance of the series:

$$
r=\mathbb{V}\left[\sum_{k} \omega_{k} \frac{\overrightarrow{\eta_{k}}}{\sum_{i} \vec{D}_{i}}\right]
$$

where $\mu$ is the renewable energy penetration and $r$ the risk. In Equations (1) and (2), $\mathbb{E}$ and $\mathbb{V}$ represent the expected value and variance operators over time. The index $k$ is a multi-index where each $k$ represents a pair $k=(i, j)$ of region $(i)$ and technology $(j) . \vec{D}_{i}$ is the demand time series for region $i, \omega_{k}$ represents the installed capacity (IC) for a region-technology pair and $\vec{\eta}_{k}$ is the capacity factor (CF) time series for a region-technology pair, so the product $\omega_{k} \vec{\eta}_{k}$ represents the generation time series for a region-technology pair. In the optimization process, the mix of IC $\left(\omega_{k}^{\text {opt }}\right)$ that minimizes the risk is identified for each penetration level, since the bi-objective optimization is approached as an iteration over individual optimization problems where $\mu$ is discretized into its possible values (the whole development of the process is shown in Appendix B of Tantet et al. [26]).

A reformulation of the expression of the risk can help separate the different components that constitute it, i.e., the variances of individual region-technology pairs and their covariances with other region-technology pairs. By definition, the risk defined as the variance can be expressed as

$$
r=\mathbb{V}\left[\sum_{k} \omega_{k} \frac{\overrightarrow{\eta_{k}}}{\sum_{i} \vec{D}_{i}}\right]=\sum_{k, l} \omega_{k} \omega_{l} \operatorname{Cov}\left(\frac{\overrightarrow{\eta_{k}}}{\sum_{i} \vec{D}_{i}}, \frac{\overrightarrow{\eta_{l}}}{\sum_{i} \vec{D}_{i}}\right)
$$

where Cov represents the covariance matrix between the series of capacity factors normalized by the demand. By definition, the covariance matrix includes all covariances between regions and technologies and also the variances of technology-region pairs. If the terms in Equation (3) are separated, the risk can be expressed as:

$$
r=\sum_{k} \omega_{k}^{2} \mathbb{V}\left(\frac{\overrightarrow{\eta_{k}}}{\sum_{i} \vec{D}_{i}}\right)+\sum_{k \neq l} \omega_{k} \omega_{l} \operatorname{Cov}\left(\frac{\overrightarrow{\eta_{k}}}{\sum_{i} \vec{D}_{i}}, \frac{\vec{\eta}_{l}}{\sum_{i} \vec{D}_{i}}\right)
$$

Therefore, the risk is expressed as the sum of the individual variances of the region-technology pairs with an extra term accounting for the covariances between them. The first term on the RHS of Equation (4) is always positively defined, as the variance is. Contrarily, the second term on the RHS shows that it is possible for the risk to be reduced (resp. augmented) by the presence of negative (resp. positive) covariances. Having non-zero $\omega_{k}$ in two negatively correlated region-technology pairs produces lower risk than the case in which they are positively correlated or even uncorrelated.

However, the definition of the optimization problem is not complete, as some constraints are necessary to make sure the optimization results represent realistic and plausible changes in the real world. First, IC is by nature a positively defined vector $\left(\omega_{k} \geq 0 \forall k\right)$. When considering a repowering scenario, where the total IC in the system is an upper bound in the optimization and at most redistributed regionally, the total IC of the mixes cannot exceed the reference total IC. In our case, the IC installed in 2018 in the Spanish electricity system is taken as the reference $\left(\omega_{\text {total2018}}\right)$. Putting together the definitions and constraints, we have the complete optimization problem used in this study:

$$
\max _{\omega_{k}} \mu
$$




$$
\begin{gathered}
\min _{\omega_{k}} r \\
\text { subject to } \omega_{k} \geq 0 \forall k \\
\text { and } \sum_{k} \omega_{k} \leq \omega_{\text {total2018 }}
\end{gathered}
$$

This mimics the basic optimization problem solved by Tantet et al. [26]. The solution to Equations (5)-(8) are the optimal energy mixes under the current climate, allowing a repowering of the whole electricity system. This assumes that the total power installed remains constant, independent of technology.

An alternative scenario is obtained when IC in the optimization process is bounded for each piece of technology (PV and wind). In that case, the total capacity constraint in Equation (8) is substituted by:

$$
\begin{gathered}
\sum_{i} \omega_{i, j=\mathrm{PV}} \leq \omega_{\text {total } \mathrm{PV}} \\
\sum_{i} \omega_{i, j=\text { wind }} \leq \omega_{\text {total } \text { wind }}
\end{gathered}
$$

This is obviously a more constrained problem than Equations (5)-(8), but its solution represents a more realistic renewable deployment mix, in the sense that the solution to Equations (9) and (10) reveals where the currently installed PV panels and wind turbines would have produced higher penetrations and lower risks to the current Spanish electricity system. It is well known that the deployment of PV and wind plants depends on many factors, with specific regional policies among them [46], but the solution to Equations (9) and (10) provides information regarding the optimal deployment of currently installed means with no inference from more socially steered decision mechanisms.

\subsection{The Pareto Front and Its Relevant Elements}

The solution of the optimization problems described above is $\vec{\omega}$ as a function of either the penetration $\mu$ or the risk (expressed here as $\sqrt{r}$ ). This is known as a Pareto front [47] and for each constraint (maximum total IC or maximum per-technology IC), a $\vec{\omega}(\mu)$ or $\vec{\omega}(\sqrt{r})$ is obtained. A useful tool to visualize the solutions of the two-parameter optimization problem (Equations (5)-(8), also in the case where (9) and (10) are used) is the so called penetration-risk diagram (Figure 1a).

Any combination of IC $(\vec{\omega})$ produces a specific penetration and risk (Equations (5) and (6)), so each $\vec{\omega}$ can be represented by a point in the two-parameter space penetration-risk diagram. A solution of the optimization problem $(\sqrt{r}(\vec{\omega}(\mu)))$ can be represented as a line in this diagram. The optimal unconstrained frontier (black line in the diagram) indicates the optimal mixes under no total installed capacity constraint (i.e., the optimization in Equations (5)-(7), without the constraint in Equation (8)).

The Pareto frontier appears linear in the penetration-risk diagram when no total capacity constraint is imposed. This is a consequence of the linear dependence of $\mu$ and $\sqrt{r}$ with $\vec{\omega}$ (Equations (5) and (6)), together with the very nature of the optimization (maximizing $\mu$ and minimizing $r$ in the calculation steps, but $\sqrt{r}$ when represented), which produces solutions of the form $\vec{\omega}=\alpha \vec{\omega}_{R E F}$ in this unconstrained case. Solutions $\omega_{k}$ along this frontier (which differ among them in the total installed capacity required to achieve each penetration/risk level) are proportional, confirming that an optimal penetration-risk relative mix (i.e., proportion of IC among regions) exists and defines the optimal regional distribution of PV and wind for each total IC capacity assumed.

The optimal unconstrained frontier divides the space in two regions. The gray region (to the left and up from the black line) is unachievable by any combination of installed capacities, independently of capacity constraints. The available climate resource and technology efficiencies in the system render a minimum possible variability for each penetration level, and thus lower levels of risk cannot be satisfied with the considered PV and wind technologies in Spain, regardless of the regional distribution of IC (i.e., $\vec{\omega}$ ). Consequently, in the context of unlimited available capacity to install, mixes that produce mean-risk values to the right and below the black line are suboptimal. When a constraint is 
applied to the total IC, regional ICs of the optimal mixes are not proportional to the penetration and risk level anymore but nonlinear trade-offs of penetration and risk emerge. The optimal constrained front (blue line) contains all points that are optimal under the conditions of the optimization problem presented in Equations (5)-(8). This again divides the parameter space into two regions. Points above and to the left of the constrained front represent unreachable mixes with the total capacity available, whereas points below and to the right of the constrained front represent suboptimal mixes. Points along the constrained front represent optimal energy mixes and the line describes the best risk level achievable at a certain penetration level, and vice versa. Mixes $\vec{\omega}$ along this line are all optimal at each predefined penetration or risk level. Therefore, it is the target level of penetration and tolerated risk set by policy makers and stakeholders that would determine the corresponding optimal IC distribution $\left(\vec{\omega}_{\text {target }}\right)$. The technology-constrained optimization process puts forward the optimal mixes from Equations (5)-(7) with the constraint modifications in Equations (9) and (10). These are the optimal mixes that are possible when the investment in renewable generation is identical to the one made in Spain, with the same wind and PV ICs as the current Spanish scenario. By definition, the technology-constrained front that results from this optimization always overlaps with the optimal capacity-constrained front or the suboptimal area. The reason for this is that more restrictions are applied and the best possible scenario is one where the optimal capacity-constrained energy mix has the same PV-wind proportion as the technology-constrained front.

We consider five mixes of special interest in the penetration-risk diagram. First, the current mix (grey circle) represents where the 2018 Spanish electricity mix is located in terms of penetration and risk. Other interesting mixes linked to the current IC can be easily identified on a mean-risk diagram. The maximum-ratio mix (black circle) represents the highest penetration mix where the capacity-constrained front and the unconstrained front overlap. This represents the energy mix that could be achieved by repowering the current installed capacity in the most optimal way, by installing all of the capacity in the optimal (unconstrained) proportion. The low-risk mix (blue and green pentagons) represents the optimal mix at the 2018 mix penetration level but with the minimal (optimal) risk. There are two low-risk mixes, one under total IC constraint and one under technology constraint. The high-penetration mix (blue and green diamonds) is the optimal mix with the current risk but maximum (optimal) penetration. Two high-penetration mixes are possible, depending on whether exchange of power between technologies is allowed (capacity-constrained) or not (technology-constrained). Finally, the free high-penetration mix (black cross) reveals the maximum penetration that the climate resource in Spain allows one to produce with PV and wind plants under the 2018 risk level. Achieving this IC regional distribution would require repowering 2018 installed capacity and installing over 12,000 MW of additional technology, but would bring the highest possible penetration to the system without assuming any further risk with respect to the 2018 level.

\subsection{Interpretation of IC Evolution}

A complementary tool to the penetration-risk diagram is the IC evolution diagram (Figure 1b), which represents the regional IC against the global penetration along a particular Pareto front.

A first general characteristic of these representations is that regional ICs are proportional at low penetration levels. At low penetrations, the optimal mixes satisfy the maximum installed capacity

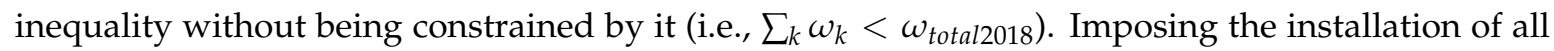
the IC of 2018 would render doubtfully relevant solutions in which capacity would be installed in suboptimal regions to meet the low penetration level with excessive total IC. This smaller installed capacity allows the system to follow the unconstrained mixes. For global penetration levels that cannot be achieved with the constrained IC and the proportional distribution of capacities from the unconstrained $\operatorname{mix}\left(\omega_{k}^{u n c}\right)$, nonlinearities between global penetration and regional installed capacities $\left(\omega_{k}\right)$ emerge. Interestingly, in high global penetration requirement cases, one region-technology pair concentrates most IC, with negligible capacities installed in the other regions. These solutions are the trivial mixes in which the global penetration is only achievable by installing capacity in the region 
and technology with the highest capacity factor. The optimization problem is in that case trivial, as only a single mix fulfills the penetration requirement, and the minimal—despite being large—risk is not determinant.

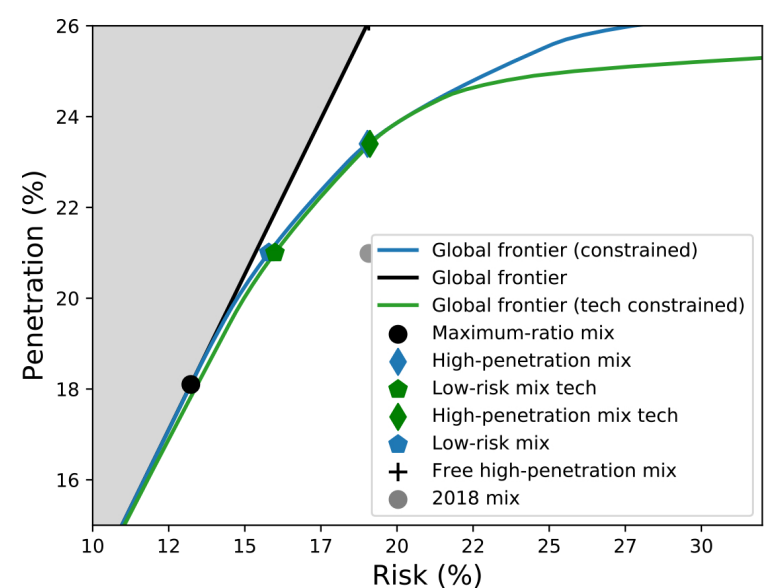

(a)

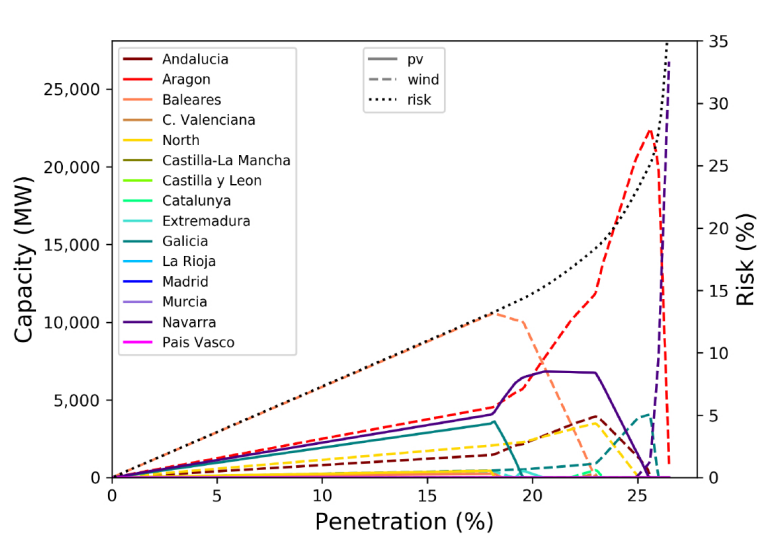

(b)

Figure 1. Standard visual representation of the optimization results. (a) CTL/CAL penetration-risk diagram with the Pareto optimal front for the two basic optimization processes. Risk is represented as $\sqrt{r}$, using standard deviation instead of variance. The blue line represents the Pareto optimal capacity-constrained front and the green line represents the Pareto optimal technology-constrained front. The black line represents the optimal unconstrained front. The black circle represents the maximum-ratio mix, the highest penetration mix where the capacity-constrained and unconstrained front overlap. The gray circle represents the $2018 \mathrm{mix}$. Blue and green pentagons represent the low-risk mix in both constrained scenarios with, respectively, optimal risk and the same penetration as the 2018 mix. Blue and green diamonds represent the high-penetration mix in both constrained scenarios with, respectively, optimal penetration and the same risk as the 2018 mix. The black cross represents the free high penetration mix, with unconstrained optimal penetration and the same risk as the 2018 mix. (b) CTL/CAL installed capacity (IC) evolution along the capacity constrained front (blue line in panel a). The dotted black line (right y axis) represents total risk of the mix. Risk is represented as $\sqrt{r}$. Dashed and solid lines (left y axis) show wind and PV ICs respectively. Colors represent regions.

A noticeable trait is also the effect of covariances between regions as a regulator of the total risk. The differences in the series of different region-technology pairs can make it easier to combine them and reduce the total variability. The role of covariances can be seen especially well in the exchange of IC as we move along the front increasing penetration. When the capacity constraint is active and one region can no longer contribute to an optimal mix due to its low generation potential, it is replaced by some other higher-penetration one. The relevant factors in determining what region this IC will be assigned to are the relation between the penetration and the variance, and the relation between the penetration and the covariances. The first consideration looks at the optimality of a region on its own, whereas the second requires deeper insight onto its role in the entirety of the system. These two different criteria to select optimal regions maintain an equilibrium in the determination of the optimal mixes. For instance, a very favorable factor for the selection of one region is its correlation to the region that can no longer take part in the optimal mix. This same procedure can be thought of in reverse. The optimization problems identify minimum risk mixes. When the decomposition of risk in Equation (4) is considered, the only contribution towards reducing the risk is either installing capacity in regions with lower variance or selecting regions with weak covariances between them. Therefore, when a region is not kept in the mix due to its low individual penetration, the ones highly correlated to it are assumed to have similarly low covariances to the rest of the mix. This yields covariances to be of critical importance when considering the minimization of the risk. 


\subsection{Unpredictable Component of the Risk}

The risk is defined in Equation (2) as the variance of the renewable resource (normalized by the demand). This definition assumes all sources of variability of the capacity factor contribute equally to the electricity system's risks. However, this could introduce misleading solutions in the optimization when the capacity factor is significantly affected by predictable components of variability. For example, the hourly wind intensity is unpredictable over climatic time spans. Nearly all wind generation variability at the hourly scale poses a risk when evaluated over decadal and larger scales. Indeed, since the percentage of covered demand varies mostly unexpectedly, it generates management costs that are implicitly parameterized by the definition of risk in Equation (2).

However, for energy sources that each have a significant component of predictable capacity factor variability, the bulk definition of risk in Equation (2) does not account for the benefits that predictable aspects of systems can offer. PV is the paradigmatic example of a highly variable source with a large proportion of its variance associated with predictable variation of the source. In particular, solar radiation can be decomposed into predictable and non-predictable components, the predictable component being very accurately represented by the clear-sky radiation [36]. The non-predictable component of the radiation is mainly dominated by cloud blocking and other radiative influential effects [37]. Therefore, not all variability sources impact the renewable penetration risks equally. Given the hypothetical example of two generation plants with equal mean capacity factor and variance, the one with more predictable variations in the generation is undoubtedly preferred over the other when looking for optimal mixes. This would be the case for twin wind and photovoltaic plants.

As a matter of fact, ignoring the differential treatment that predictable variations in an energy source allows in mean-variance optimization problems undermines the identification of truly optimal renewable energy mixes of a system, penalizing more predictable sources.

Now let us assume two regions, one with very high peak radiation values and one with very low ones, and both regions showing no cloud cover, so the radiation arriving at surface is the clear-sky radiation. The variance of the high-production series will be significantly larger than that of the low-production series, but this difference will be smaller in the mean. This is due to the effect of the night, which keeps differences in the mean limited. Although the difference in the amplitude will be taken into account in the penetration, in terms of risk both regions are following their predictable behavior with the clear-sky cycle of radiation; however, they are being penalized differently.

A more illustrative example of this can be to take a region with clear-sky radiation and the same region showing cloud coverage on some days. The penetration (mean) for both series will be very similar-only slightly lower for the cloud-covered version due to the moderating effect of the nights and the days where cloud is not present. However, overall, the contribution to the variance will be significantly smaller since the observed radiation will always be closer to the mean. The introduction of cloud coverage always acts as a factor that reduces the variance, so regions with cloud coverage are favored, despite their unpredictable nature. A graphical representation of this can be seen in Figure 2a. The ratio between the mean and the standard deviation (we use the standard deviation $\sqrt{r}$ as a representation of the risk for clarity) is higher for clear-sky radiation than for cloud-covered radiation. In an optimization process of these two radiative inputs, the cloud-covered one is generally favored-only losing its predominant position at very high penetration levels where installing all the ICs in this region could not satisfy the penetration required. Predictable variability can be planned around, making its handling more efficient, besides being used in the planning of the use of resources. However, the introduction of unpredictable factors requires exceptional measures by the system, which can experience unexpected behaviors with very little warning and needs to be able to cope with them. These types of unpredictable effects pose additional challenges to the system, and larger investments are required in order to cope with them. 


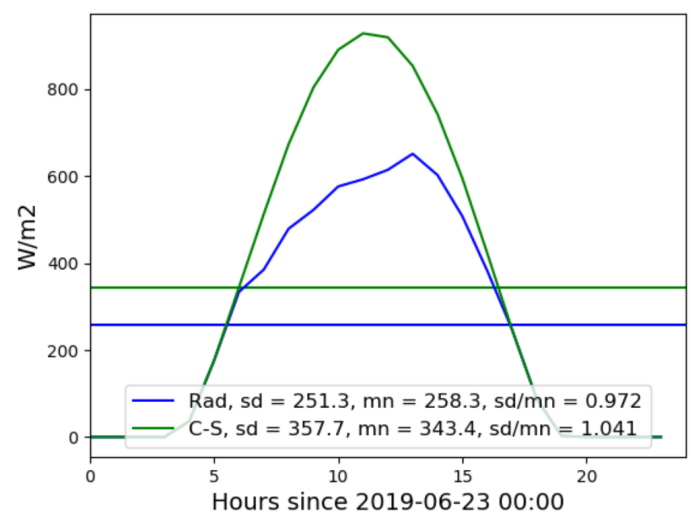

(a)

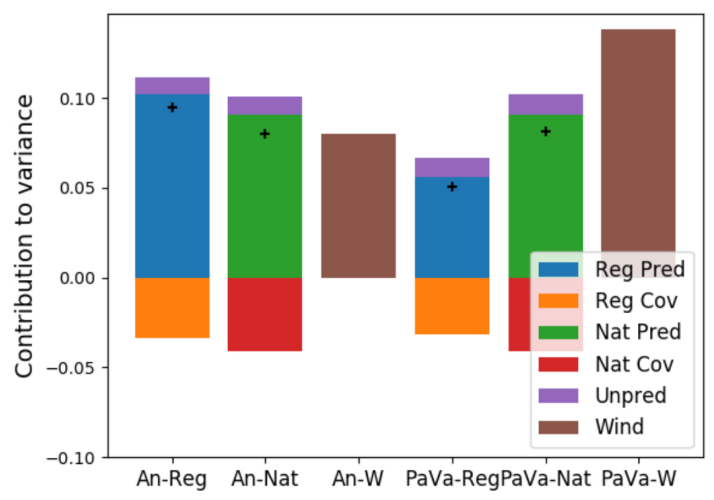

(b)

Figure 2. Analysis of the (a) motivation and (b) effect of the proposed methodology. (a) Hourly values of MERRA-2 surface downward shortwave solar radiation (blue line) and clear-sky values (green line) for an sample illustrative day. Daily means are represented with horizontal lines. Inset table includes a legend and the statistical summary for the two series-mean (mn), standard deviation (sd) and the ratio between the two. (b) Analysis of the contributions to the regional variance for Andalucia (An) and Pais Vasco (PaVa). An-Reg and PaVa-Reg show: regional predictable (blue), regional unpredictable (purple) and covariance between them (orange). An-Nat and PaVa-Nat show: national-averaged predictable (green), regional unpredictable (purple) and national-averaged regional covariances between predictable and unpredictable contributions (red). Black crosses represent the additions of all the terms of the variance. An-W and PaVa-W show the total variance of the wind generation in brown bars.

We propose an alternative definition of risk that more precisely accounts for the most damaging impacts of the variability of renewable energy sources. This assumes that the impacts associated with the variability of the predictable component of the CF can be more easily mitigated at the planning stage than the non-predictable part. It is of crucial importance that the IC is allocated in the right areas, since the balancing costs (linked to fast unforeseen variations of the resource) represent the most easily deductible costs of the system. However, it is true that the largest amount of system cost in the renewables comes from the fact that conventional power plants remain indispensable independently of the range of penetration, the so-called "utilization effect" [44]. Exchange of electricity at different temporal and spatial scales is key in the path towards a higher renewable penetration system [48]. Following the objective of reducing the easily avoidable cost of the system in the unpredictable variability, a new risk definition is proposed.

Since the wind has no predictable components at hourly frequency over climatic time spans, this definition regards the PV generation only in our model. In particular, the PV contribution to the risk associated with a particular mix is calculated using the unpredictable component of the total surface radiation.

Given a region, we can separate its PV generation $(x)$ into two different components,

$$
\vec{x}=\vec{x}_{P}-\vec{x}_{N P}
$$

where $\vec{x}_{P}$ is the predictable generation and $\vec{x}_{N P}$ is the unpredictable component, which is the difference between the predictable and the observed generation. $\vec{x}$ is defined as the difference between its predictable and unpredictable components in order to consider the clear-sky generation as the predictable component and the unpredictable component as a positively-defined perturbation that always has a reducing effect on the predictable component. This effect always contributes towards reducing the radiation; the minus sign is explicit in Equation (11), so $\vec{x}_{N P}$ is non-negative. 
Using this notation, the new definition of risk from unpredictable component of energy sources is:

$$
r_{P V}=\mathbb{V}\left[\sum_{i} \omega_{i} \frac{\vec{\eta}_{i}\left(\vec{x}_{N P}\right)}{\sum_{i} \vec{D}_{i}}\right]
$$

This definition embraces the concept of risk as the probability of the occurrence of something unaccounted for and more difficult to cope with than predictable variations.

This definition of risk is illustrative of the concept, and applicable to energy systems based on single means of generation, in which regions with larger predictable variability would be arbitrarily penalized in the original optimization problem. An example is a hypothetical system based only on PV, where the definition in Equation (12) would not penalize southern regions against northern regions for having larger average daily radiative oscillations as does Equation (2). However, removing a substantial part of the variability for some solutions in an optimization problem that minimizes variance (as in Equation (12)) introduces a significant favorable bias for the technologies presenting a predictable component, independently of the magnitude of such component when compared to other possibly less variable but nevertheless unpredictable technologies.

Admittedly, the variance of the predictable component of an energy source poses some management challenges that must also be taken into account in the energy mix optimization problem. Entirely removing the variance of the predictable part of an energy source produces an overcorrection that is unrealistic, especially when the mix contains technologies with distinct proportions of predictable versus unpredictable components.

To take this into consideration, and combine the need to account for a contribution to the variance from the predictable component but not in a manner that penalizes regions and technologies with larger $\vec{x}_{P}$, we use a reference $\vec{x}_{P}^{*}$ across regions:

$$
\vec{x}^{*}=\vec{x}_{P}^{*}-\vec{x}_{N P}
$$

This reference $\vec{x}_{P}^{*}$ is intended to account for the predictable component of a technology, though discarding intra-regional differences. A practical definition of $\vec{x}_{P}^{*}$ is to use the national (energy system wide) mean of $\vec{x}_{P_{i}}$. The application of Equation (13) to PV renders an $\vec{x}_{P}^{*}$ equal to the national mean of the clear-sky radiation based generation. A reason why it is important to include a form of the daily cycle, besides the aforementioned comparability to other sources, is that the resource will be lacking during night hours and energy supply should remain covered. In other words, other energy sources need to be available when PV is not, even when this unavailability is predictable.

The particular definition of the reference predictable component may have counterintuitive impacts through the covariance term between the two components:

$$
r_{P V}=\mathbb{V}\left(\vec{x}^{*}\right)=\sigma_{\vec{x}^{*}}^{2}=\sigma_{\vec{x}_{P}^{*}}^{2}+\sigma_{\vec{x}_{N P}}^{2}-2 \operatorname{cov}\left(\vec{x}_{P}^{*}, \vec{x}_{N P}\right)
$$

When $\overrightarrow{x_{P}^{*}}$ and $\overrightarrow{x_{N}} P$ are highly covariant, the total variance is reduced, and that scenario is favored by the optimization problem. That is precisely the case when $\overrightarrow{x_{P}^{*}}$ is the PV generation from an average clear-sky source (astronomical daily cycle) and $x_{N} P$ is the PV generation deficit attributable to cloudiness and other CF reduction factors (non-zero values only during the day). Therefore, this term will promote regions with generation deficits in the optimization problem not because of more convenient generation properties, but due to the covariances of the predictable and unpredictable components of the renewable source.

To overcome this, the regional covariance term between predictable and unpredictable components in the risk calculation is replaced by a nation-wide average:

$$
r_{P V}=\sigma_{\vec{x}_{P}^{*}}^{2}+\sigma_{\vec{x}_{N P}}^{2}-2\left\langle\operatorname{cov}\left(\vec{x}_{P}^{*}, \vec{x}_{N P}\right)\right\rangle_{R}
$$


Similarly to the case with the predictable cycle, the covariance term is replaced by its national mean to account for the comparability to other energy sources together with the need to have other sources available when PV is predictably unavailable. This is accounted for by replacing the different variance terms with national averages and not removing them altogether. This proposed definition of risk allows us to give separate treatment to the predictable and non predictable components of a renewable source such as PV, thereby keeping the ability to compare them to other sources in a mean-variance optimization problem. A visual representation of the effect of this decomposition on two different regions can be seen in Figure 2b. The risk definition in Equation (15) expresses the core novelty of the proposed method, which uses only unpredictable variability as a distinction between regions and therefore does not disfavor regions on account for their predictable cycles.

\subsection{Optimization Experiments}

The motivation and impacts of the new risk definition are illustrated by our optimization experiments. For the sake of readability of the text, experiments are labeled with acronyms (Table 1).

Table 1. List of experiments performed in this study. An additional NEW/UNIEFF experiment is discussed and based on the NEW/NOCAL with uniform efficiencies across regions. CNT and NEW refer to the risk definition being used, with original (control) risk and new risk definition, respectively. If only a PV optimization was carried out, the experiment is labeled PV; the lack of such a label implies the appearance of wind. Two labels relative to the radiation in original risk PV-only experiments are used, CS for the case with the clear-sky radiation and OR for the original radiation case. CAL and NOCAL determine whether calibration was carried out or not, respectively, in an optimization for PV and wind.

\begin{tabular}{ccccccc}
\hline Experiment & Calibration & PV & Wind & Risk & Radiation & Pareto Front \\
\hline CNT/CAL & YES & YES & YES & Original & MERRA-2 & Figure 1a \\
CNT/NOCAL & NO & YES & YES & Original & MERRA-2 & Figure 4a \\
CNT/PVCS & NO & YES & NO & Original & Clear-sky & Figure 5a \\
CNT/PVOR & NO & YES & NO & Original & MERRA-2 & Figure 5b \\
NEW /PV & NO & YES & NO & Non-predictable & Both & Figure 6a \\
NEW/NOCAL & NO & YES & YES & Non-predictable & Both & Figure 7a \\
NEW $/$ CAL & YES & YES & YES & Non-predictable & Both & Figure 8a \\
\hline
\end{tabular}

\section{Impacts on Optimal Renewable Energy Mixes}

The solutions to the penetration-risk optimization problem are highly sensitive to the definition of risk. Installed capacities in optimal energy mixes can be hauled across regions and exchanged among technologies when new risk definition refinements are introduced. Here, we analyze the impacts of the multiple risk considerations made in Section 2.

\subsection{Optimal Mixes for Spain with the Original Risk Definition}

The 2018 (reference) mix of the PV and wind technologies in Spain shows a very diverse distribution, with at least some installation of each piece of technology in practically all regions (Figure 3a). Regional policies with incentives for renewable installation are an important cause for this distribution. 


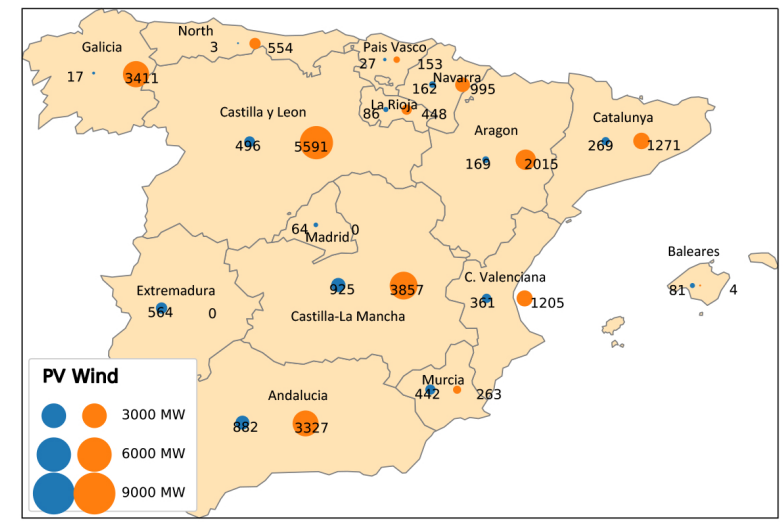

(a)

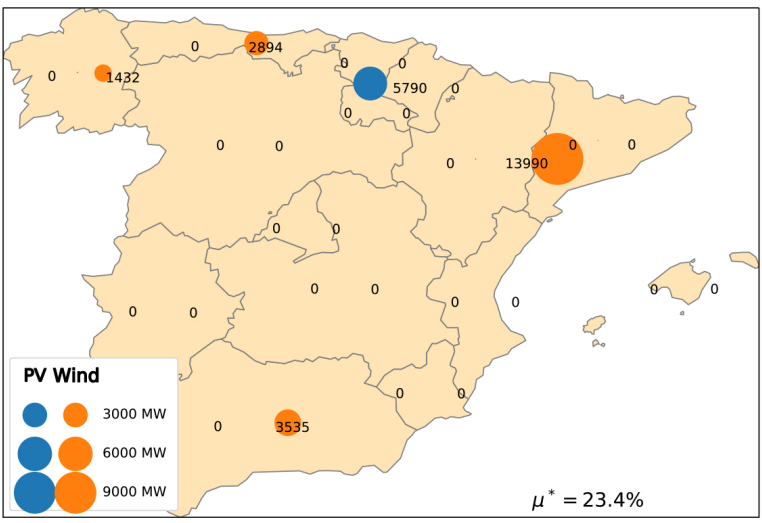

(c)

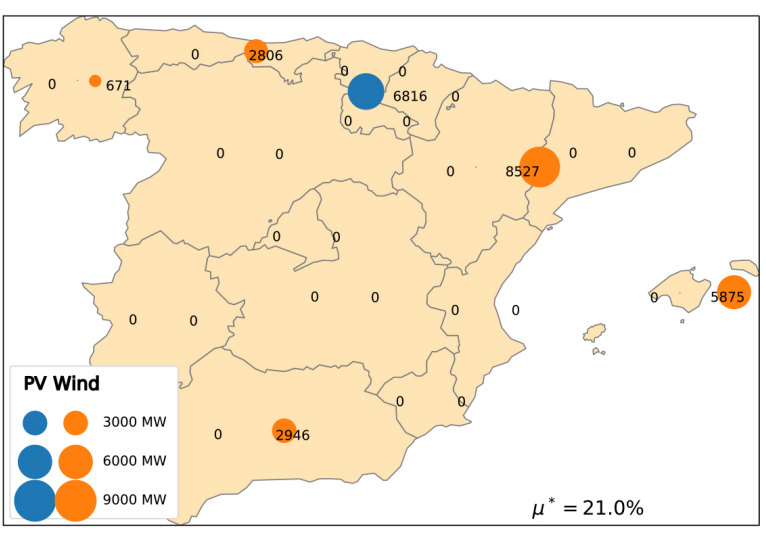

(b)

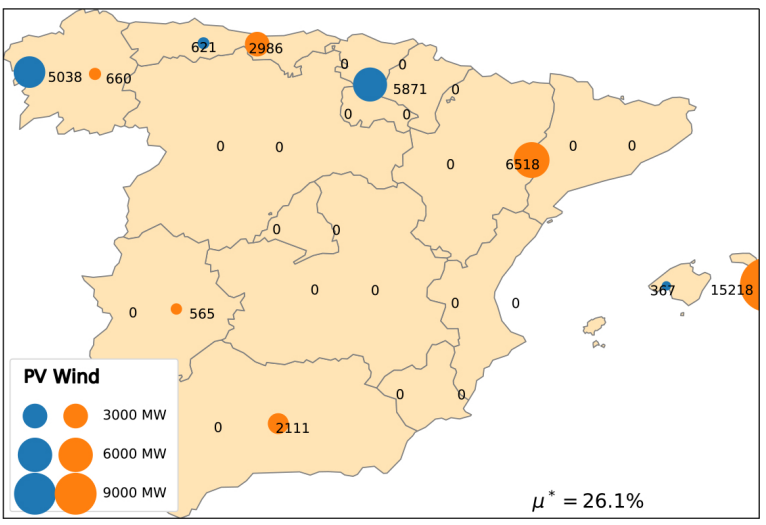

(d)

Figure 3. Maps representing renewable IC in Spain for PV (blue) and wind (orange). (a) REE-reported 2018 mix. CTL/CAL (b) low-risk, (c) high-penetration and (d) free high-penetration mixes.

An application of the mean-variance optimization as presented in Tantet et al. [26] to the Spanish PV-wind energy mix (i.e., Equations (5)-(8)) is first introduced as the control experiment (CTL/CAL).

The solution to CTL/CAL (Figure 1a) reveals that major improvements compared to the actual mix could be obtained by means of a simple redistribution, whether only geographical or a full repowering of the system was applied. More specifically, the low-risk mix would represent a drop with respect to current risk by around $20 \%$. In the case of the high-penetration scenario, it represents an increase of the current penetration of around $10 \%$, which means that a significantly higher renewable penetration would be possible while assuming no further system risk. Overall significant improvements with respect to the current mix could be achieved through a repowering process or could have been achieved by national coordination with a higher degree of influence of mean-variance analysis results.

The distribution of PV installed capacities along the capacity constrained front (Figure 1b) focuses on two regions: Navarra and Galicia (see Figure 3a for reference location). Both are located on the northern side of the Iberian Peninsula and do not have particularly high values of radiation comparatively. Although their efficiency is higher than other regions with greater radiative exposure, their average generation is still significantly lower than in these southern regions. This suggests that the higher generation regions are being penalized for their higher variability. However, this larger variability caused by a highly predictable larger daily cycle amplitude of the radiative resource should be treated differently to the variability injected by unpredictable generation means. The part of this variability that is favoring these regions is a combination of their lower daily radiation cycle combined with a larger presence of cloud cover, similarly to the case shown in Figure 2a.

Maps contribute to better visualizing this geographical distribution of installed capacities associated with particular mixes. The low-risk mix (Figure 3b) locates all PV capacity in the northern 
region of Navarra. This allocation may not be surprising since northern regions could be expected to be associated with lower risks. However, the high-penetration scenario (Figure 3c) also results in all PV IC in Navarra. Moreover, the free high-penetration mix (Figure 3d), a sample of the unconstrained optimal mix, shows an even larger deployment towards northern regions. These regions present radiation cycles with lower amplitudes and higher cloud coverage with respect to their southern counterparts, which are clear indications of dysfunction in the risk assessment of the penetration-risk analysis, which penalizes excessively large predictable daily cycles, despite its predictability.

\subsection{Experiments with Non-Calibrated Mixes}

In order to illustrate the differences in using the original and new definitions of risk, and for the sake of clarity, the calibration of climate-driven generation is not applied. This prevents the calibration from covering up the true effects of the new risk definition.

\subsubsection{No-Calibration PV-Wind Original Optimization for Spain}

The Pareto fronts for the experiment with original risk definition and no calibration (CONOCAL; Figure 4a) do not differ significantly in terms of shape and values from those of the control experiment. This, however, does not necessarily imply similar mixes.

The comparison of the optimal mixes resulting from calibrated against non-calibrated generation series reveals some interesting aspects and limitations of the modeling framework. The PV IC in Navarra and wind IC in Aragon (Figure 4b) showed insensitivity to the calibration process for these two experiments. However, the Balearics showed great sensitivity to the calibration, as the climate-driven data for that region had a bias towards a maritime environment due to the spatial resolution limitations of MERRA-2, which attributed to the region a larger wind generation potential than the one actually registered by REE. Interestingly, these resolution limitations act in the opposite direction in Andalucia and the northern regions, where MERRA-2 data do not resolve local persistent winds responsible for the higher generations reported in these regions by REE. As a consequence, the calibration process modified the climate-estimated CFs by reducing the wind CF in the Balearics and increasing it in Andalucia and the northern regions.

Besides these illustrative examples, the calibration allows us to correct limitations in the climate-driven CF regarding intra-regional resource heterogeneity and the availability of suitable installation areas in the territory. More specifically, the calibration of climate-driven generation data for Spain tends to promote the wind over PV basically because wind production is frequently underestimated, as actual wind plants are not generally installed in average sites within the region (better represented by MERRA-2 data) but in selected areas with local climate characteristics favorable for wind generation.

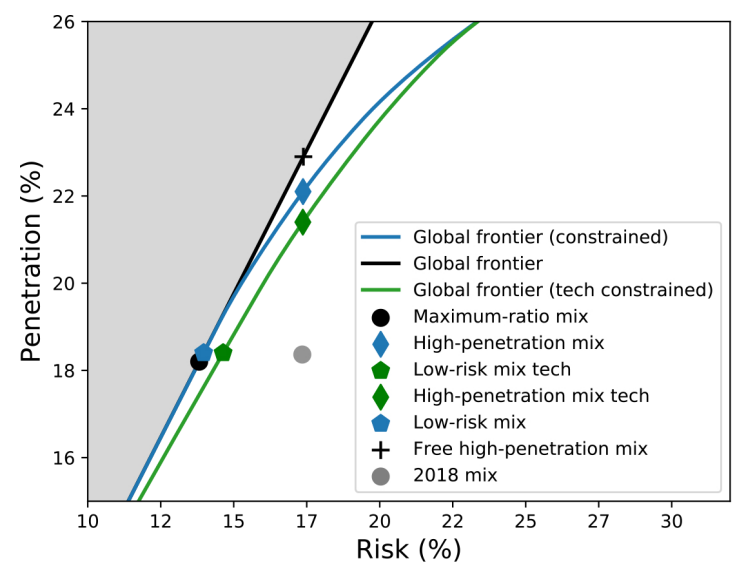

(a)

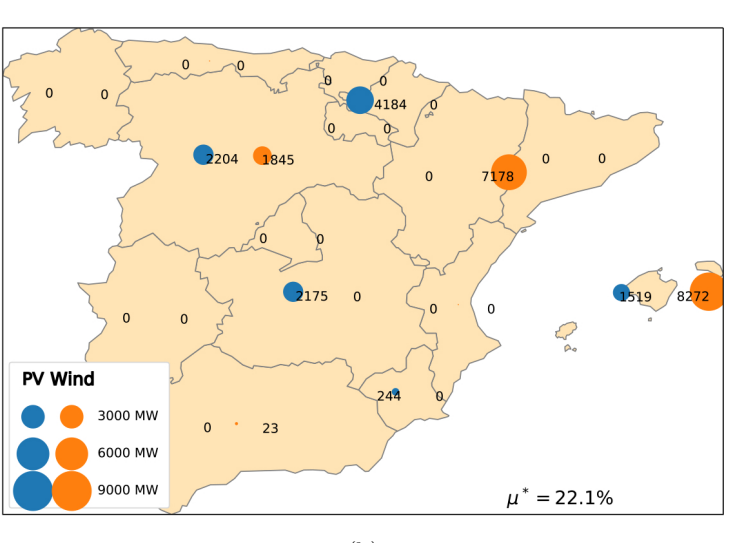

(b)

Figure 4. CONOCAL (a) penetration-risk diagram and (b) high-penetration mix. 


\subsubsection{Effect of Radiation on the Optimization}

The effect of the PV risk $\left(r_{P V}\right)$ on the optimization becomes explicit when only PV is considered. With the approach of optimizing for a PV geographical repowering, the effects of the risk on the mean-variance analysis can be observed. Two experiments were designed with this goal, wherein the optimization problem with the original risk definition was solved first, using the clear-sky radiation (CTL/PVCS; Figure 5a), and second, the observed radiation (CTL/PVOR; Figure 5b) was used to illustrate the weaknesses of the original risk definition.

The first remarkable difference with respect to the front in CONOCAL (Figure 4a) is the magnitude that the penetration and the risk have. The fact that the PV total capacity in the 2018 Spanish mix is fairly low leads to some limitations to the IC. A noticeable difference between the two different radiation experiments is that CTL/PVCS (Figure 5a) penetrations and risks are higher than CTL/PVOR (Figure 5b). This was an expected result given the higher amplitude of the clear-sky radiation with respect to the actual value, by definition.

Clear-sky radiation is the most predictable form of solar radiation. In a repowering scenario, the predictability of the renewable resource and its high return are precisely valuable assets that are pursued when PV technology is installed.

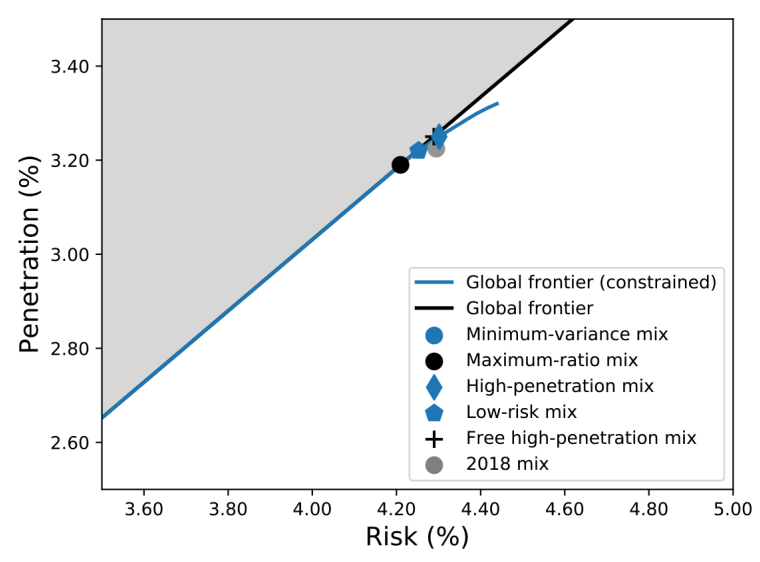

(a)

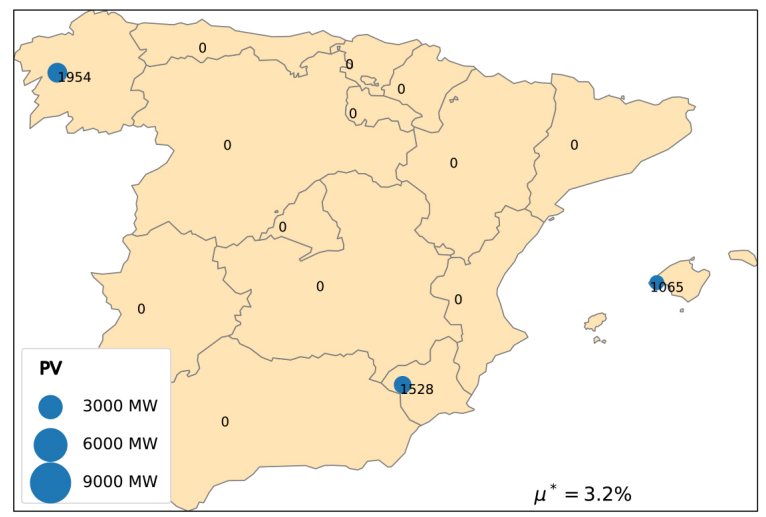

(c)

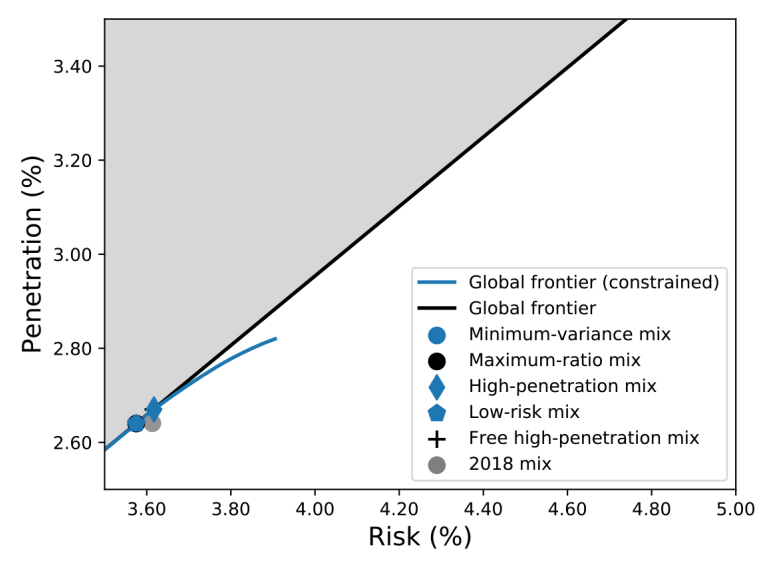

(b)

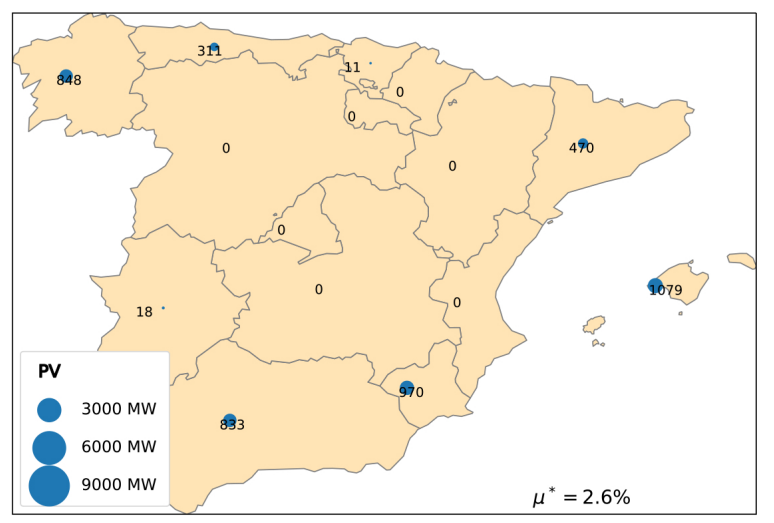

(d)

Figure 5. Penetration-risk diagram $(\mathbf{a}, \mathbf{b})$ and high penetration mix $(\mathbf{b}, \mathbf{d})$ for CTL/PVCS $(\mathbf{a}, \mathbf{c})$ and CTL/PVOR (b,d).

The regional distribution of PV IC in the high-penetration mix for CTL/PVCS (Figure 5c) and CTL/PVOR (Figure 5d) differs significantly from the PV IC distribution in CONOCAL (Figure 4b). A detailed analysis of the covariance matrix clearly revealed that this difference is partly due to the correlations between PV and wind generation and the higher availability of IC. 
The high-penetration mix for CTL/PVCS (Figure 5c) shows a disperse distribution of IC, with sites in Galicia, the Balearics and Murcia. The Balearics appear in the mix as the region with the most favorable mean-risk ratio, and Galicia as its complementary region due to their high correlation. Murcia appears as the region with the best mean-risk ratio out of the high-penetration regions. In general terms, this mix distributes PV IC into one northern region, the Balearics and one southern region.

The high penetration mix for CTL/PVOR (Figure 5d) differs significantly for the clear-sky mix. Overall capacity is more uniformly distributed, although the general north-south distribution remained the same as for CTL/PVCS experiment. The effect of clouds is a redistribution in the northern and southern areas to further spread out the IC. More specifically, four northern regions and three southern ones show PV IC in this experiment, compared to the single northern and southern ones in CTL/PVCS. The change in the north-south redistribution is not significant, with roughly the same IC in both areas as in the clear-sky case.

The comparison of CTL/PVCS with CTL/PVOR underlines the dysfunction described in Section 2 and produced by the excessive attribution of risk to larger amplitude intermittent renewable sources from predictable components. These results shed light on the research question of this study and motivated the proposal for an alternative definition of risk, accounting for the practical differences between predictable and non-predictable components of the resource.

\subsubsection{A Comparable Version of Risk from Unpredictable Variability}

The definition of variance as risk for PV sets the path for a redefinition that especially penalizes unpredictable variability. However, the variance of unpredictable variability in itself is significantly lower than the variance of any other technology (for instance, wind) whose variance is a valid proxy for the risk. Therefore, the definition in Equation (15) aims at maintaining a comparable value for the risk while not favoring regions with larger unpredictable energy resource.

An experiment using the risk definition in Equation (15) and allowing PV technology installation was designed (NEW/PV; Figure 6a). The Pareto fronts are very similar to CTL/PVOR, although with total overlap between the constrained and unconstrained fronts. This reveals that the constraint on the IC is not effective in the constrained solution, indicating that the optimal penetration-risk levels can be achieved without installing all available capacity. The role of total capacity constraint in this case is to limit the span of penetrations achievable by the constrained problem when all capacity is installed in the region with higher $\mathrm{CF}$, and thus to discontinue the line. The regional distribution for the high-penetration mix of NEW/PV (Figure 6b) shows a focus of all the available capacity in only one region, Murcia. The regional distribution of the IC is independent of the penetration levels achieved-higher or lower penetrations only represent more or less IC—but it is always installed in Murcia. This allocation is aligned with the fact that Murcia presents high radiative exposure with scarce cloud coverage.

In order to assess the impact of the proposed definition of risk in the mean-variance analysis problem when applied on the combined PV and wind energy Spanish system, we devised a new experiment (NEW/NOCAL; Figure 7a). As expected from the definition, the solutions for this experiment show lower values of risk for all relevant mixes. Admittedly, the quantitative value of the risk is irrelevant because it varies with the definition. However, the differences in the distribution of ICs in the solutions of the optimization problem are highly informative. Considering this PV risk definition, the current penetration could be achieved with around $20 \%$ less risk. Similarly, the risk that is currently being assumed could yield penetrations around $20 \%$ higher. 


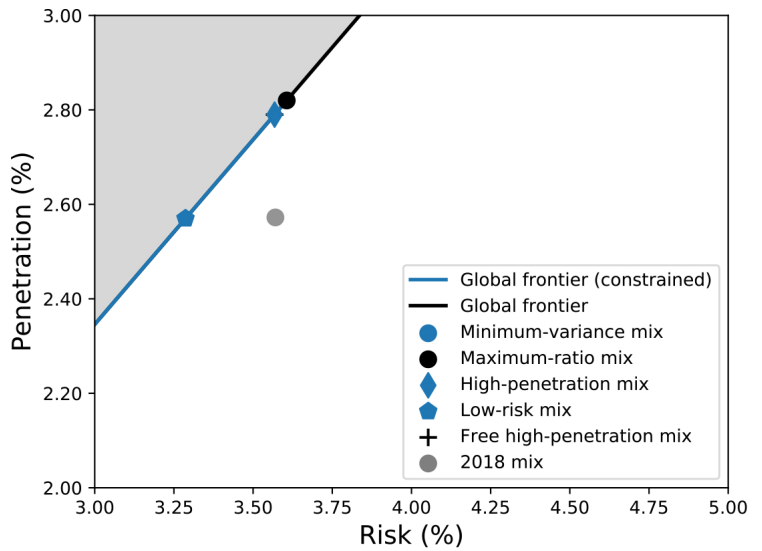

(a)

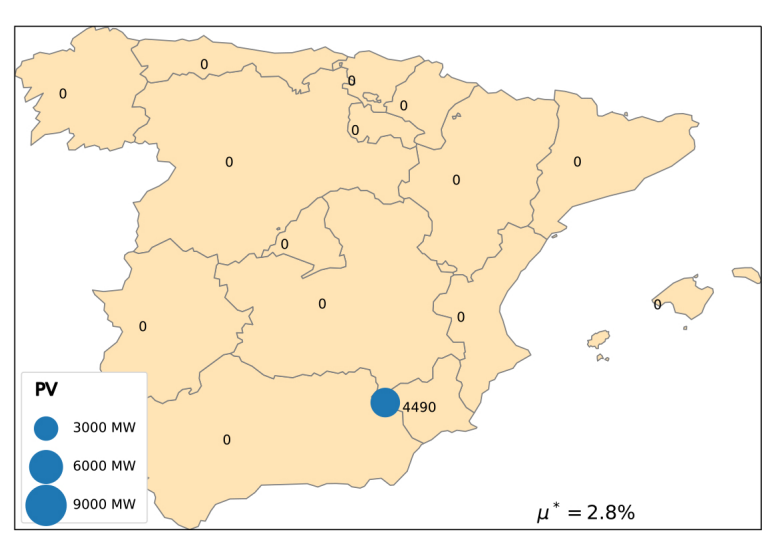

(b)

Figure 6. NEW/PV (a) penetration-risk diagram and (b) high-penetration mix.

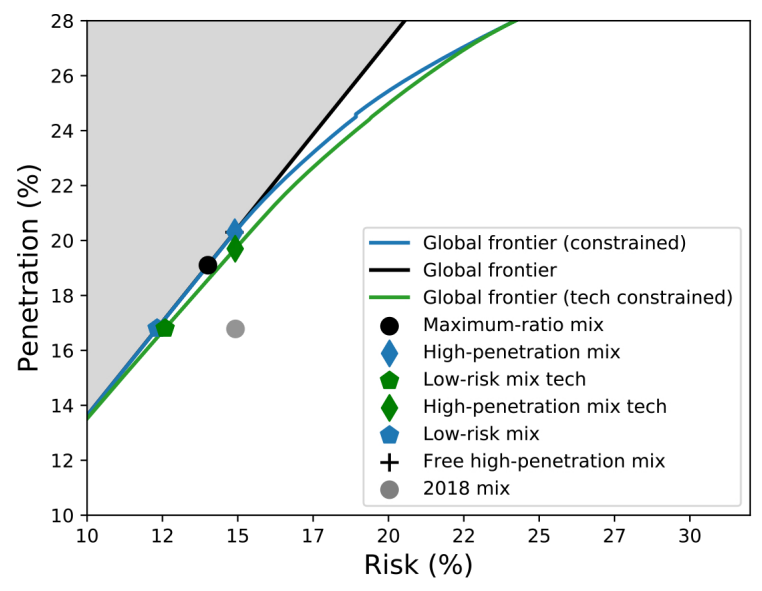

(a)

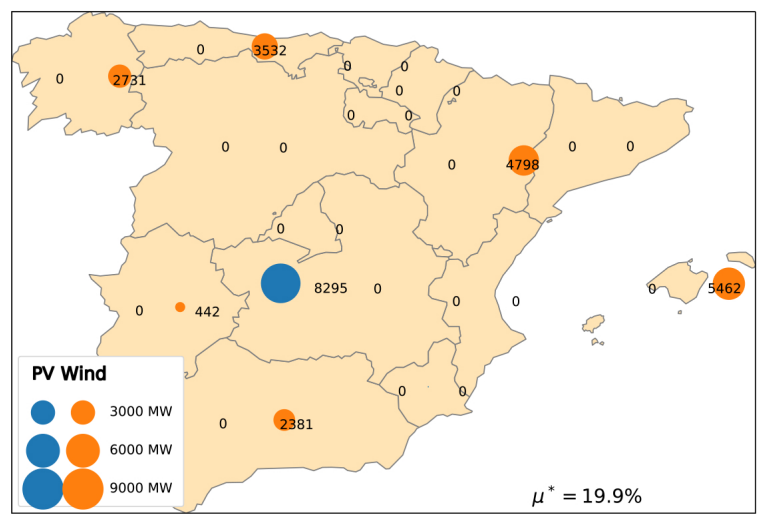

(c)

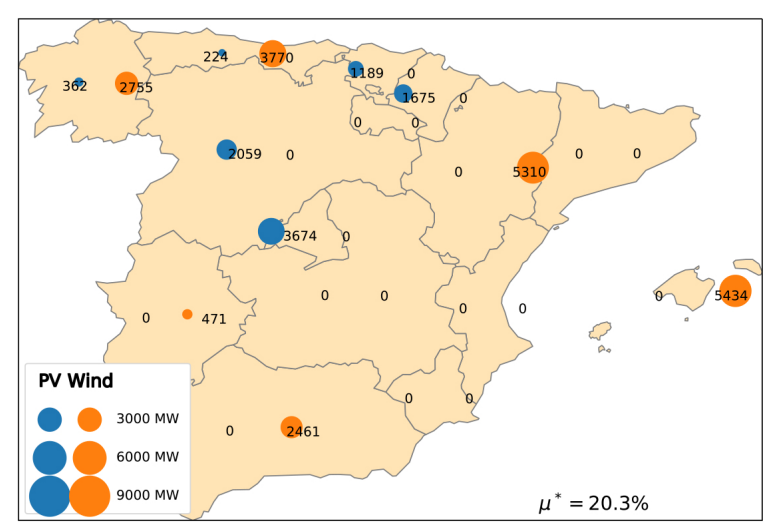

(b)

Figure 7. NEW/NOCAL (a) penetration-risk diagram and (b) high-penetration mix. (c) NEW/UNIEFF high-penetration mix.

The geographical distribution of IC in the high-penetration mix (Figure $7 \mathrm{~b}$ ) reveals that the majority of the PV technology is shifted towards the north-west of Spain with respect to CONOCAL. This PV distribution seems counter-intuitive at first glance, since the regions with the largest radiation are located towards the southern side of Spain. However, a closer analysis of the components that form PV generation can help understand this scenario. In the experiment where only PV technology was present, it was the only possible option to satisfy the demands accounted for by renewable energy sources. Therefore, the PV IC not only had to be the most optimal but also had to reach a certain 
level of penetration, since no other technology could contribute. Once wind technology is brought into the mix, it can contribute to reaching the necessary renewable penetration, and therefore PV distribution can lean towards more convenient locations despite the lower return. Southern regions present greater radiative resources but also higher temperatures when the sun exposure is maximal. As a consequence, it is possible for the higher cloud presence of northern regions during the summer months to be more beneficial than the low efficiency of southern regions. Moreover, during summer months, when radiation is largest, daily maximum temperatures in the northern regions are very similar to the optimal operating temperature of PV cells (about $25^{\circ} \mathrm{C}$ ).

In order to better illustrate the role of the efficiency in the optimization problem, we conducted a complementary experiment with uniform efficiency in all regions (NEW/UNIEFF), without climate dependence. In this experiment, PV generation depended solely on radiation and drove the geographical distribution of the IC in the optimal mixes. The change in the PV distribution in the optimal mixes (high penetration mix as example; Figure 7c) is very significant. When the temperature dependency of efficiency is not considered, the PV is all located in Castilla-La Mancha, one of the regions with the most radiative resource. Therefore, the regional distribution of PV IC is largely affected by the high sensitivity the efficiency of PV panels show with respect to air temperature. Southern regions of Spain, despite having superior radiative exposure, also have excessive maximum temperatures that penalize the efficiency and their presence in optimal scenarios.

\subsection{Calibrated, Unpredictable Risk Optimal Mixes}

The experiments presented in the previous sections allowed us to analyze the effects of predictable and unpredictable components of the risk and underline the necessity for a different definition of risk. In this section the mean-variance analysis is applied to the control experiment but using the definition of risk in Equation (15) (NEW/CAL) in order to visualize how the risk definition affects the optimal mixes in a context where calibration is present.

The results for NEW/CAL (Figure 8a) present the possibility for a rise by around $20 \%$ of the penetration or a drop by around $25 \%$ of the risk using the newly proposed definition. These results show similar values to those shown by the original risk definition (CTL/CAL) in Figure 1a. However, this does not necessarily imply that the resulting mixes from both definitions are similar. This can be seen when comparing the regional distribution of IC along the capacity constrained front (Figure 8b). NEW/CAL optimal solutions show a large presence of PV in Navarra and Extremadura at low penetrations (both contributions being significant, only overcome by the wind in the Balearics) which decreases as the penetration grows larger, and the capacity is necessarily constrained. Comparatively, in the CTL/CAL distribution (Figure 1b) Galicia and Navarra present PV technology, but show smaller ICs in the CTL/CAL unconstrained mix than in the NEW/CAL one. In the CTL/CAL unconstrained mix, wind in two regions provides a larger contribution to the mix than the regions with PV technology, implying a less relevant role of PV technology in CTL/CAL than in NEW/CAL. In this case, the PV behavior seems particularly different between both regions, as Navarra increases its IC after the mix is already constrained, compared to Galicia whose IC goes to zero as soon as the total capacity is constrained. This behavior is also different from that shown by Navarra and Extremadura in the front with the new definition of risk.

The evolution of IC along the capacity constrained front in NEW/CAL is shown in Figure 8b. In this case, the unconstrained mix consists of PV IC in Navarra and Extremadura, and wind IC in a variety of regions, with the Balearics having the greatest presence and there being capacity installed in northern and southern regions, all of which have important either coastal or mountain influences. At very high penetrations, most of the installed capacity in the optimal mixes is based on wind technology, as it provides higher levels of generation. 
The low-risk scenario (Figure 9a) shows a wind IC distribution identical to the one in CTL/CAL (Figure 3b). However, the PV IC is divided between Navarra and Extremadura, compared to its presence solely in Navarra obtained in the CTL/CAL and northern regions for the NEW/NOCAL experiment.

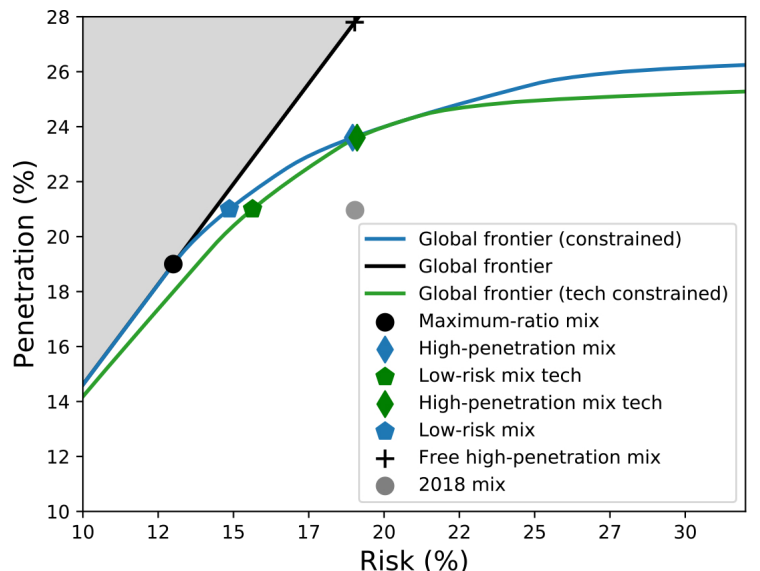

(a)

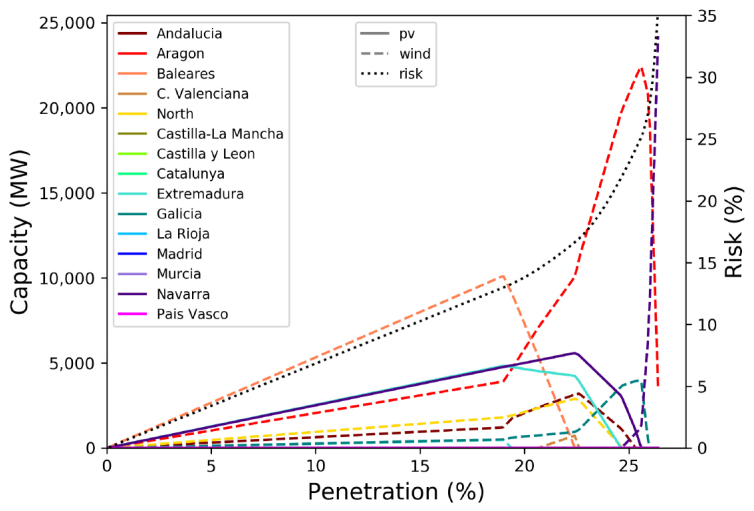

(b)

Figure 8. NEW/CAL (a) penetration-risk diagram and (b) high-penetration mix.

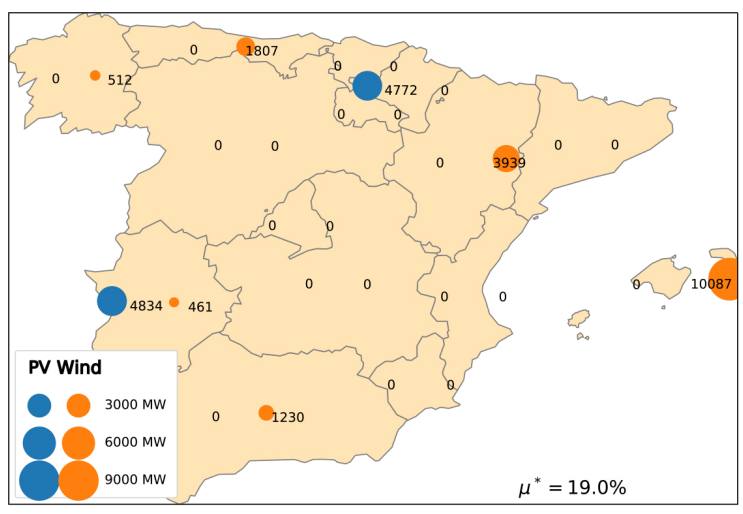

(a)

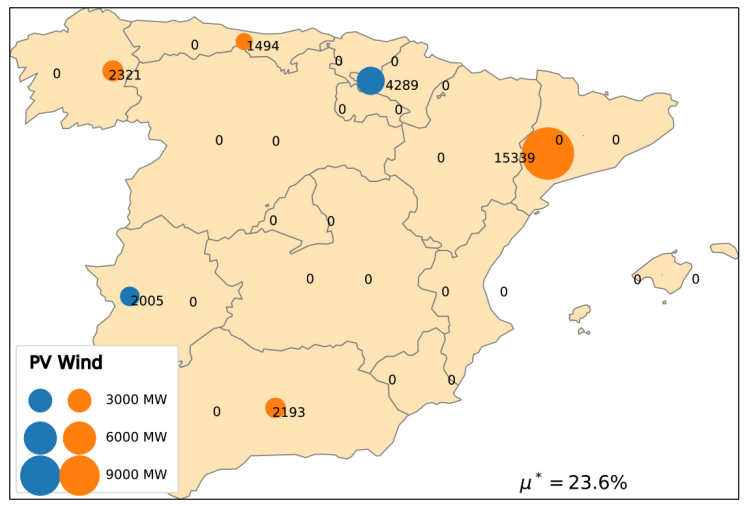

(c)

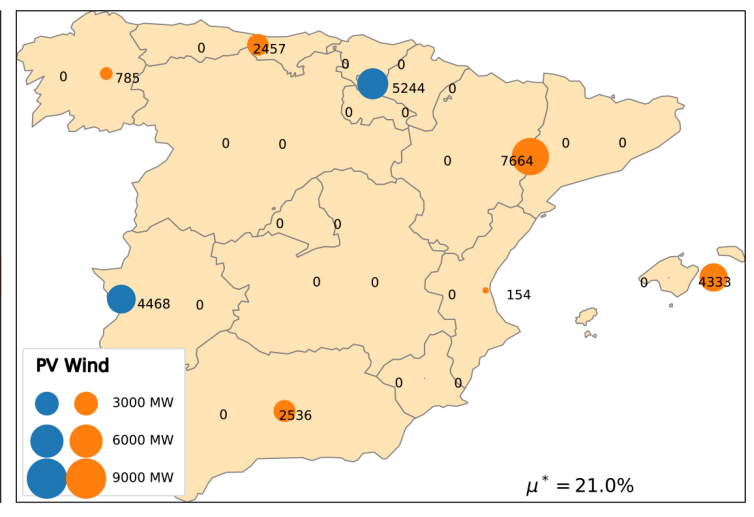

(b)

Figure 9. NEW/CAL (a) low-risk mix, (b) high-penetration mix and (c) free high-penetration mix. 
The high-penetration scenario (Figure 9b) again displays a redistribution of PV technology with respect to CTL/CAL (Figure 3c). Wind distribution is only slightly modified, with the wind installation in Extremadura being redistributed among all other regions where wind was already present, and C. Valenciana takes up a small amount of wind IC as well. These small discrepancies with respect to CTL/CAL can be attributed to the variation of PV not particularly affecting the wind IC distribution. Additionally, some PV IC is moved from Extremadura in the control experiment toward Navarra, although both regions retain some PV IC.

The free high-penetration scenario (Figure 9c) represents the specific values of the unconstrained mix where the assumed risk is the same as for the actual 2018 mix. This scenario again is very similar to the low-risk and high-penetration with PV in Extremadura and Navarra, and wind in Galicia, North, Aragon and Andalucia. The wind in Aragon presents the largest IC, whereas the Balearics have no IC in this optimal mix due to their low levels of available climate resource.

Overall, when calibration with registered electricity data is reactivated, the number of regions that remain in the mix are the same. The effect of the calibration step is large and causes some regions to stand out and remain alone in the optimal mixes. Particularly, PV in Navarra is very highly favored by the calibration process. This calibration effect in Navarra is consistently seen in CTL/CAL and NEW/CAL experiments. Therefore, although risk redefinition manages to reallocate some of the PV IC, the calibration shows the largest contribution to the IC distribution. However, differences appear with respect to CTL/CAL, showing that using the proposed risk definition helps us to introduce a new interpretation of optimal mixes under this interpretation of risk.

\section{Summary and Conclusions}

In a world with increasing needs for efficient renewable energy deployment, portfolio theory sets out a very attractive path for decision-making in terms of renewable energy penetration and regional capacity allocation. e4clim is a model that aims at evaluating and optimizing energy deployment strategies with higher shares of variable renewable energies, through assessing the impacts of new technologies and of climate variability and conducting sensitivity studies. Its current implementation of the mean-variance optimization avoids solving a full-mix cost-minimization problem by taking the mean and variance of the renewable production-demand ratio as proxies to renewable energy penetration and risk to the electrical system. This approach is simple and powerful, but further refinements are needed to take into consideration the different accountability the predictable component of the variance must have on the risk estimation. In this sense, we propose a new risk parameterization method which reduces the penalty associated with the predictable component of the generation sources in the mean-variance optimization problem. The proposed definition removes the intraregional differences originating from the predictable component of the resource, thereby avoiding the preference for lower-amplitude against higher-amplitude oscillating energy sources due to reduced variance. Such is the case for solar incoming radiation and the preference of the optimization problem to include regions with significant climatological cloud cover in the optimal mixes due to the diminishing effect of the cloud cover on the variance, the original proxy for risk.

The impacts on the solutions of the mean-variance optimization problem of linking the definition of risk more closely to the unpredictable component of the energy sources were investigated by analyzing multiple portfolios. In the original version of risk, all factors reducing the resource variability, even cloud cover for PV generation, contributed favorably due to the risk definition. The proxy for risk proposed in this study does not penalize regions with large radiative daily cycle. In particular, the proposed definition favors mixes that each have a larger component of predictable generation, which implicitly assumes the more manageable and easy to cope with challenges this variance poses to the electrical system, as opposed to the unpredictable variability modes. The conducted experiments showcase the sensitivity of the optimization to the risk definition and put forward the importance of interpreting the optimal mixes in alignment with the risk consideration. The way the risk is defined affects the decision making that lies behind selecting the optimal mix that will be pursued. It is a subtle 
but significant detail that can help discern the optimal mix for a particular situation among a collection of them.

Our results confirm that the optimal mixes of variable renewable energies which account for the predictability of the resource provide more weight to the PV technology and northern regions than the full variance definition. This unexpected result was derived from the effect of low covariances between the PV generation in these northern regions and the wind generation in other highly productive regions. However, the optimization with the proposed risk definition selects these scenarios by means of more realistic optimality and the daily cycle is not being penalized. Our experiments show that the selected mixes also benefit from the good combination that spans from these regions interacting with the installed wind technology. Undoubtedly, the definition of variable renewable energy deployment plans is not only a scientific question. Besides the identification of optimal deployments in the maximum penetration minimum risk sense, the portfolios show the relevance of multiple socioeconomical and political factors which appeared in the conducted experiments in the form of calibration and play a role in the determination of the optimality of a specific region. However, the results of this study underline the necessity to deal with the variability of predictable and unpredictable components of renewable energy sources separately, since the predictable variability of an energy source should be considered at the planning stage in order to mitigate its associated intrinsic impact on the electric system. The criteria to identify optimal regional deployment scenarios should account for the unpredictable and inherently damaging variations that can cause failures in the electricity supply. The distinction between the predictable and unpredictable components of generation is key from an energy mix design and management point of view. Not accounting for this important distinction drives the installation towards suboptimal scenarios, since it highlights areas with lower resources as having strictly lower risk as well. This result does not accurately represent the risk of PV generation, since two areas following their daily cycles should also be considered as having the same risk.

The method that we propose in this study offers the main advantage of allowing regions with the largest PV resources to be distinguished in the model. This also implies that the regions with high PV generation are not penalized in the optimization problem simply by having this higher generation. Admittedly, given the absolute priority of quality of service, the identification of optimal mixes basically reduces to economic criteria. An introduction of cost as a regulator term would allow one to compare the actual cost of introducing batteries or of transport, both of which are not considered in this approach. Additionally, fossil fuel technologies are treated in this study as an external factor to the renewable deployment, but the introduction of cost would also allow for a more intricate approach to renewable optimal mixes. Nevertheless, the climate-oriented proposed technique allowed for the valuable first investigation of the treatment of variability components in the selection of optimal energy mixes.

Our research raises the question about risk management in portfolio analysis. Future work should consider the costs of renewable installations, storage and the fossil-based technologies that are used to mitigate the intermittent nature of renewables in order to more accurately assess the actual feasibility of the different options and find optimal mixes that better fit a cost-based risk definition, a very common approach in real-life applications. For instance, this approach could help distinguish the optimal between scenarios where high production peaks and batteries are installed and scenarios with lower but sustained generation and a significantly lower investment in storage. Additionally, further research into the implications of renewable penetration EU and national policies is needed (an example for the case of Lithuania can be seen in Gaigalis and Katinas [49]). Furthermore, AI-based methods such as SVM kernel soft computing models [50] and deep echo state network [51] should be considered in future research for their promising results and potential, as they seem to commonly outperform more traditional methods of renewable generation prediction. Moreover, further investigation is necessary to find the best approach for the risk definition while taking into account the inherent climate characteristics. 
Multi-decadal (climatic) time scales are relevant for the long-term investment in renewable-energy capacities (i.e., the optimization of the capacity distributions). On such long time scales, the astronomical cycles are undeniably predictable, but the statistics of the wind and PV production are also predictable to a large extent, given our knowledge of climatology. This means that the system could be dimensioned to handle not only the astronomical cycles but also to cope with the variability of the wind production. This implies having enough reserves [52] and efficient balancing and intra-day markets, possibly thanks to long-term capacity markets to encourage investment in balancing capacities. Once these long-term investments are made and that the system is prepared to cope with variability, short-term prediction models (day-ahead, intraday) are needed to be able to use these mechanisms as efficiently as possible when the time comes. However, this short-term production is beyond the scope of this study and could be considered in future work.

Both demand and renewable generation depend strongly on climate features, making them fundamental components of the electricity system that should be further investigated. Climatic expertise from the scientific community should be further integrated into the renewable energy deployment optimization, considering the relevant role of climate as the power source for the renewable energy technologies.

Author Contributions: Conceptualization, A.M.-F., A.T., V.H. and P.D.; methodology, A.M.-F., A.T., V.H. and P.D.; software, A.M.-F. and A.T.; validation, A.M.-F.; investigation, A.M.-F.; data curation, A.M.-F. and A.T.; writing - original draft preparation, A.M.-F. and V.H.; writing — review and editing, A.M.-F., A.T., V.H. and P.D.; visualization, A.M.-F.; supervision, V.H. and P.D.; project administration, V.H.; funding acquisition, V.H. and P.D. All authors have read and agreed to the published version of the manuscript.

Funding: This research was partially funded by COASTEPS-CGL2017-82868-R Project, supported by the Agencia Estatal de Investigación, Spanish Ministry of Science, Innovation and Universities; and partially supported with ERDF funds and grant number FPU 18/00520 from the Spanish Ministry of Science, Innovation and Universities.

Acknowledgments: The authors acknowledge Red Eléctrica de España for supplying the Spanish electricity data. This work is also a contribution of the Energy4Climate Interdisciplinary Center (E4C) of IP Paris and Ecole des Ponts ParisTech. It was supported by 3rd Programme d'Investissement d'Avenir (ANR-18-EUR-006-02).

Conflicts of Interest: The authors declare no conflict of interest.

\section{References}

1. IEA. World Energy Outlook 2019; IEA: Paris, France, 2019; ISBN 978-92-64-97300-8.

2. IEA. Global Energy Review 2020; IEA: Paris, France, 2020. Available online: https: / / www.iea.org/reports/ global-energy-review-2020 (accessed on 2 July 2020).

3. IRENA. Global Renewables Outlook: Energy Transformation 2050; IRENA: Abu Dhabi, UAE, 2020; ISBN 978-92-9260-238-3.

4. European Commission. Clean Energy for All Europeans. 2019; ISBN 978-92-79-99835-5. Available online: https:/ / ec.europa.eu/energy/topics/energy-strategy/clean-energy-all-europeans_en (accessed on 16 June 2020).

5. European Commission. A Clean Planet for All. A European Strategic Long-Term Vision for a Prosperous, Modern, Competitive and Climate Neutral Economy. COM/2018/773 Final; 2018. Available online: https: / / eur-lex.europa.eu/legal-content/EN/TXT/?uri=CELEX\%3A52018DC0773 (accessed on 17 June 2020).

6. European Commission. Report from the Commission to the European Parliament, the Council, the European Economic and Social Committee, the Committee of the Regions and the European Investment Bank. Fourth Report on the State of the Energy Union; COM/2019/175 Final; 2019. Available online: https: / / op.europa.eu/en/publication-detail/- / publication/8263aedc-5ab2-11e9-9151-01aa75ed71a1 (accessed on 18 June 2020).

7. Cramer, W.; Guiot, J.; Fader, M.; Garrabou, J.; Gattuso, J.; Iglesias, A.; Lange, M.; Lionello, P.; Llasat, M.; Paz, S.; et al. Climate change and interconnected risks to sustainable development in the Mediterranean. Nat. Clim. Chang. 2018, 8, 972-980. [CrossRef]

8. Tuel, A.; Eltahir, E.A.B. Why Is the Mediterranean a Climate Change Hot Spot? J. Clim. 2020, 33, 5829-5843. [CrossRef]

9. Jansa, A.; Homar, V.; Romero, R.; Alonso, S.; Guijarro, J.A.; Ramis, C. Extension of summer climatic conditions into spring in the Western Mediterranean area. Int. J. Climatol. 2017, 37, 1938-1950. [CrossRef] 
10. United Nations Environment Programme. Mediterranean Strategy for Sustainable Development 2016-2025. 2016; ISBN 978-92-807-3576-5. Available online: https:/ / planbleu.org/sites/default/files/publications / mssd_2016-2025_final.pdf (accessed on 28 June 2020).

11. Ministerio para la transición ecológica y el reto demográfico. Plan Nacional Integrado de Energía y Clima (PNIEC) 2021-2030. 2020. Available online: https://www.idae.es/informacion-y-publicaciones/plannacional-integrado-de-energia-y-clima-pniec-2021 \-2030 (accessed on 23 June 2020).

12. Gómez, A.; Zubizarreta, J.; Dopazo, C.; Fueyo, N. Spanish energy roadmap to 2020: Socioeconomic implications of renewable targets. Energy 2011, 36, 1973-1985. [CrossRef]

13. Plan nacional de Adaptación al Cambio Climático 2021-2030. 2020. Available online: https:/ / www.miteco. gob.es/es/cambio-climatico/participacion-publica/PNACC.aspx (accessed on 23 June 2020).

14. Datas, A.; Ramos, A.; del Cañizo, C. Techno-economic analysis of solar PV power-to-heat-to-power storage and trigeneration in the residential sector. Appl. Energy 2019, 256, 113935. [CrossRef]

15. Santiago, I.; Trillo-Montero, D.; Moreno-Garcia, I.; Pallarés-López, V.; Luna-Rodríguez, J. Modeling of photovoltaic cell temperature losses: A review and a practice case in South Spain. Renew. Sustain. Energy Rev. 2018, 90, 70-89. [CrossRef]

16. Santos-Alamillos, F.J.; Pozo-Vázquez, D.; Ruiz-Arias, J.A.; Lara-Fanego, V.; Tovar-Pescador, J. Analysis of Spatiotemporal Balancing between Wind and Solar Energy Resources in the Southern Iberian Peninsula. J. Appl. Meteorol. Climatol. 2012, 51, 2005-2024. [CrossRef]

17. IEA. Technology Roadmap-Solar Photovoltaic Energy. 2014. Available online: https://www.iea.org/ reports/technology-roadmap-solar-photovoltaic-energy-2014 (accessed on 17 June 2020).

18. Agency, I.E. Technology Roadmap Wind Energy; International Energy Agency: Paris, France, 2015. [CrossRef]

19. Pariente-David, S. Successful Grid Integration of Renewable Energy:Integration is the Name of the Game, International Association for Energy Economics (IAEE) Energy Forum; IAEE: Dallas, TX, USA, 2014.

20. Jurasz, J.; Canales, F.; Kies, A.; Guezgouz, M.; Beluco, A. A review on the complementarity of renewable energy sources: Concept, metrics, application and future research directions. Solar Energy 2020, 195, 703-724. [CrossRef]

21. Zedda, S. Portfolio strategies for renewable energy share maximization. In Proceedings of the 2019 1st International Conference on Energy Transition in the Mediterranean Area (SyNERGY MED), Cagliari, Italy, 28-30 May 2019; pp. 1-4. Available online: https://ieeexplore.ieee.org/document/8764128 (accessed on 30 June 2020).

22. Ruiz-Arias, J.; Terrados, J.; Pérez-Higueras, P.; Pozo-Vázquez, D.; Almonacid, G. Assessment of the renewable energies potential for intensive electricity production in the province of Jaén, southern Spain. Renew. Sustain. Energy Rev. 2012, 16, 2994-3001. [CrossRef]

23. François, B.; Borga, M.; Creutin, J.; Hingray, B.; Raynaud, D.; Sauterleute, J. Complementarity between solar and hydro power: Sensitivity study to climate characteristics in Northern-Italy. Renew. Energy 2016, 86, 543-553. [CrossRef]

24. Raynaud, D.; Hingray, B.; François, B.; Creutin, J. Energy droughts from variable renewable energy sources in European climates. Renew. Energy 2018, 125, 578-589. [CrossRef]

25. Markowitz, H. PORTFOLIO SELECTION*. J. Financ. 1952, 7, 77-91. [CrossRef]

26. Tantet, A.; Stéfanon, M.; Drobinski, P.; Badosa, J.; Concettini, S.; Cretì, A.; D'Ambrosio, C.; Thomopulos, D.; Tankov, P. E4CLIM 1.0: The energy for a climate integrated model: Description and application to Italy. Energies 2019, 12, 4299. [CrossRef]

27. Beltran, H.A. Modern Portfolio Theory Applied to Electricity Resource Planning. Master's Thesis, University of Illinois, Urbana-Champaign, IL, USA, 2009.

28. Roques, F.; Hiroux, C.; Saguan, M. Optimal wind power deployment in Europe-A portfolio approach. Energy Policy 2010, 38, 3245-3256. [CrossRef]

29. Roques, F.A.; Newbery, D.M.; Nuttall, W.J. Fuel mix diversification incentives in liberalized electricity markets: A Mean-Variance Portfolio theory approach. Energy Econ. 2008, 30, 1831-1849. [CrossRef]

30. Thomaidis, N.S.; Santos-Alamillos, F.J.; Pozo-Vázquez, D.; Usaola-García, J. Optimal management of wind and solar energy resources. Comput. Oper. Res. 2016, 66, 284-291. [CrossRef]

31. Santos-Alamillos, F.; Thomaidis, N.; Usaola-García, J.; Ruiz-Arias, J.; Pozo-Vázquez, D. Exploring the mean-variance portfolio optimization approach for planning wind repowering actions in Spain. Renew. Energy 2017, 106, 335-342. [CrossRef] 
32. Muñoz, J.I.; de la Nieta, A.A.S.; Contreras, J.; Bernal-Agustín, J.L. Optimal investment portfolio in renewable energy: The Spanish case. Energy Policy 2009, 37, 5273-5284. [CrossRef]

33. Marrero, G.A.; Puch, L.A.; Ramos-Real, F.J. Mean-variance portfolio methods for energy policy risk management. Int. Rev. Econ. Financ. 2015, 40, 246-264. [CrossRef]

34. Kitzing, L. Risk implications of renewable support instruments: Comparative analysis of feed-in tariffs and premiums using a mean-variance approach. Energy 2014, 64, 495-505. [CrossRef]

35. Heide, D.; Greiner, M.; Bremen, L.; Hoffmann, C. Reduced storage and balancing needs in a fully renewable European power system with excess wind and solar power generation. Renew. Energy 2011, 36, 2515-2523. [CrossRef]

36. Wilber, A.C.; Smith, G.L.; Gupta, S.K.; Stackhouse, P.W. Annual Cycles of Surface Shortwave Radiative Fluxes. J. Clim. 2006, 19, 535-547. [CrossRef]

37. Papadimas, C.D.; Fotiadi, A.K.; Hatzianastassiou, N.; Vardavas, I.; Bartzokas, A. Regional co-variability and teleconnection patterns in surface solar radiation on a planetary scale. Int. J. Climatol. 2010, 30, 2314-2329. [CrossRef]

38. Lave, M.; Kleissl, J. Solar variability of four sites across the state of Colorado. Renew. Energy 2010, 35, 2867-2873. [CrossRef]

39. Fthenakis, V.; Mason, J.E.; Zweibel, K. The technical, geographical, and economic feasibility for solar energy to supply the energy needs of the US. Energy Policy 2009, 37, 387-399. [CrossRef]

40. Steinke, F.; Wolfrum, P.; Hoffmann, C. Grid vs. storage in a 100\% renewable Europe. Renew. Energy 2013, 50, 826-832. [CrossRef]

41. Chen, H.; Cong, T.N.; Yang, W.; Tan, C.; Li, Y.; Ding, Y. Progress in electrical energy storage system: A critical review. Prog. Nat. Sci. 2009, 19, 291-312. [CrossRef]

42. Dunn, B.; Kamath, H.; Tarascon, J.M. Electrical Energy Storage for the Grid: A Battery of Choices. Science 2011, 334, 928-935. [CrossRef]

43. van Stiphout, A.; De Vos, K.; Deconinck, G. The Impact of Operating Reserves on Investment Planning of Renewable Power Systems. IEEE Trans. Power Syst. 2017, 32, 378-388. [CrossRef]

44. Sijm, J. Cost and Revenue Related Impacts of Integrating Electricity from Variable Renewable Energy into the Power System-A Review of the Recent Literature. ECN-E 14-022 2014. Energy Cent. Ned. 2014. Available online: https: / publications.tno.nl/publication/34629263/8pk15B/e14022.pdf (accessed on 24 June 2020).

45. Gelaro, R.; McCarty, W.; Suárez, M.J.; Todling, R.; Molod, A.; Takacs, L.; Randles, C.A.; Darmenov, A.; Bosilovich, M.G.; Reichle, R.; et al. The Modern-Era Retrospective Analysis for Research and Applications, Version 2 (MERRA-2). J. Clim. 2017, 30, 5419-5454. [CrossRef]

46. Perpiñá Castillo, C.; Silva, F.; Lavalle, C. An assessment of the regional potential for solar power generation in EU-28. Energy Policy 2016, 88, 86-99. [CrossRef]

47. Miettinen, K. Nonlinear Multiobjective Optimization; Kluwer Academic Publishers: Boston, MA, USA, 1999. Available online: https:/ / www.springer.com/gp/book/9780792382782 (accessed on 5 July 2020).

48. Holttinen, H.; Meibom, P.; Orths, A.; Lange, B.; O’Malley, M.; Tande, J.O.; Estanqueiro, A.; Gomez, E.; Söder, L.; Strbac, G.; et al. Impacts of large amounts of wind power on design and operation of power systems, results of IEA collaboration. Wind Energy 2011, 14, 179-192. [CrossRef]

49. Gaigalis, V.; Katinas, V. Analysis of the renewable energy implementation and prediction prospects in compliance with the EU policy: A case of Lithuania. Renew. Energy 2020, 151, 1016-1027. [CrossRef]

50. Natarajan, Y.J.; Nachimuthu, D.S. New SVM kernel soft computing models for wind speed prediction in renewable energy applications. Soft Comput. 2019, 1-18. [CrossRef]

51. Hu, H.; Wang, L.; Lv, S.X. Forecasting energy consumption and wind power generation using deep echo state network. Renew. Energy 2020, 154, 598-613. [CrossRef]

52. Frunt, J.; Kling, W.; van den Bosch, P. Classification and quantification of reserve requirements for balancing. Electr. Power Syst. Res. 2010, 80, 1528-1534. [CrossRef]

(C) 2020 by the authors. Licensee MDPI, Basel, Switzerland. This article is an open access article distributed under the terms and conditions of the Creative Commons Attribution (CC BY) license (http:/ / creativecommons.org/licenses/by/4.0/). 